
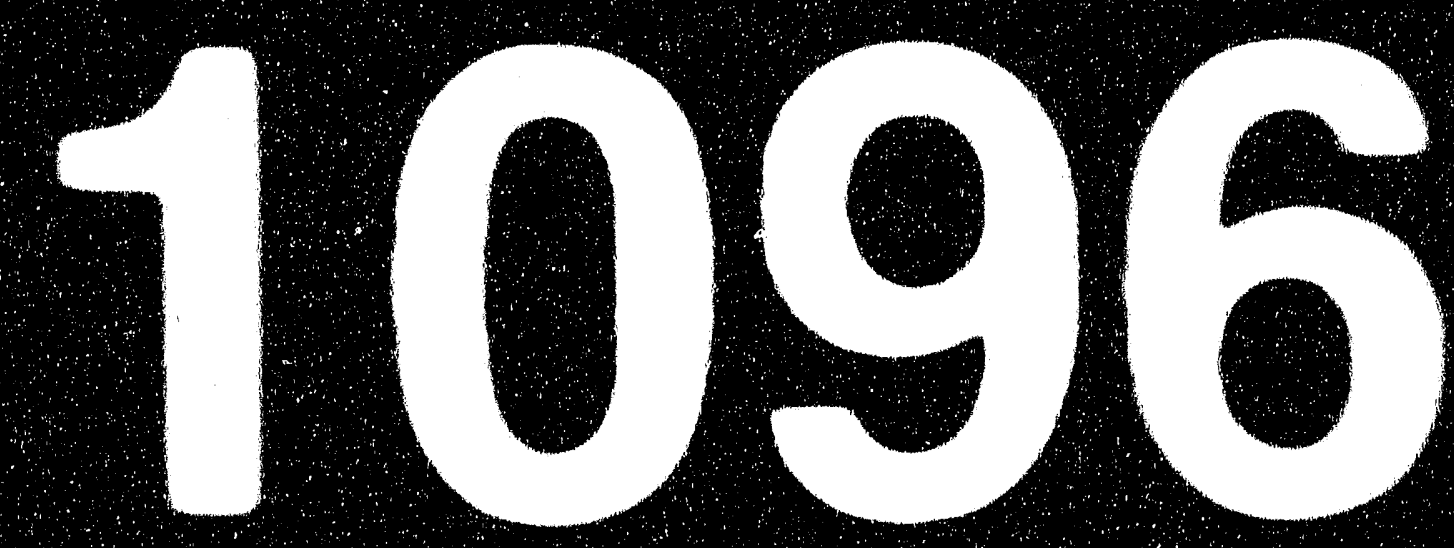

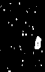

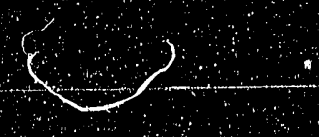

\title{
1
}
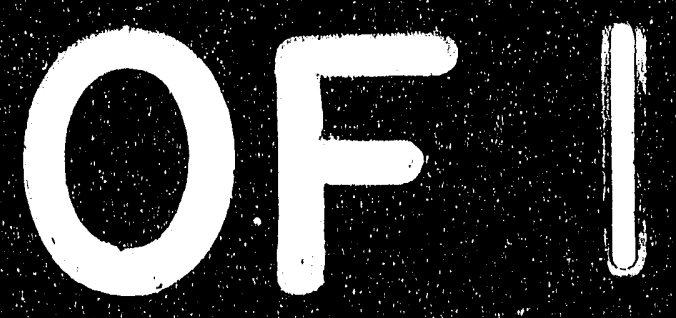

1

$<$

1

2



\|\|$\| 1.25$

8

0.

3

3

a

\%

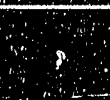


FEB O 39982

$$
\text { DOE/PC/ }\left.\right|_{1} 5952 \cdots T 2
$$

INNOVATIVE CLEAN COAL TECHNOLOGY (ICCT) DE92 010961

\section{DEMONSTRATION OF SELECTIVE CATALYTIC REDUCTION (SCR) \\ TECHNOLOGY FOR THE CONTROL OF NITROGEN OXIDE (NOX) \\ EMISSIONS FROM HIGH-SULFUR COAL-FIRED BOILERS}



Patents Cleared by Chicago on November 18, 1991




This report was prepared by Southern Company Services, Inc. pursuant to a cooperative agreement partially funded by the U.S. Department of Energy and neither Southern Company Services, Inc. nor any of its subcontractors nor the U.S. Department of Energy, nur any person acting on behalf of either:

(a) Makes any warranty or representation, express or implied with respect to the accuracy, completeness, or usefulness of the information contained in this report, or that the use of any information, apparatus, method, or process disclosed in this report may not infringe privately-owned rights; or

(b) Assumes any liabilities with respect to the use of, or for damages resulting from the use of, any information, apparatus, method or process disclosed in this report.

Reference herein to any specific commercial product, process, or service by trade name, trademark, manufacturer, or otherwise, does not necessarily constitute or imply its endorsement, recommendation, or favoring by the U.S. Department of Energy. The views and opinion of authors expressed herein do not necessarily state or reflect those of the U.S. Department of Energy. 


\section{Section 1}

SUMMARY

The objective of this project is to demonstrate and evaluate commercially available Selective Catalytic Reduction (SCR) catalysts from U. S., Japanese and European catalyst suppliers on a high-sulfur U. S. coal-fired boiler. SCR is a post-combustion nitrogen oxide (NOx) control technology that involves injecting ammonia into the flue gas generated from coal combustion in an electric utility boiler. The flue gas containing ammonia is then passed through a reactor that contains a specialized catalyst. In the presence of the catalyst, the ammonia reacts with NOx to convert it to nitrogen and water vapor.

Although SCR is widely practiced in Japan and Europe, there are numerous technical uncertainties associated with applying SCR to U. S. coals. These uncertainties include:

(1) potential catalyst deactivation due to poisoning by trace metal species present in U.S. coals that are not present in other fuels.

(2) performance of the technology and effects on the balance-ofplant equipment in the presence of high amounts of $\mathrm{SC}_{2}$ and $\mathrm{SO}_{3}$.

(3) performance of a wide variety of SCR catalyst compositions, geometries and methods of manufacture under typical highsulfur coal-fired utility operating conditions.

These uncertainties will be explored by constructing a series of smal1-scale SCR reactors and simultaneously exposing different SCR catalysts to flue gas derived from the combustion of high sulfur U. S. coal.

The demonstration will be performed at Gulf Power Company's Plant Crist Unit No. 5 (75 MW capacity) near Pensacola, Florida. The project will be funded by the U.S. Department of Energy (DOE), Southern Company Services, Inc. (SCS on behalf of the entire Southern electric system), and the Electric Power Research Institute (EPRI). SCS is the participant responsible for managing all aspects of this project. 
The project is being conducted in the following three phases:

\author{
Phase I - Permitting, Environmental Monitoring Plan and Preliminary \\ Engineering \\ Phase II - Detailed Design Engineering and Construction \\ Phase III - Operation, Testing, Disposition and Final Report
}

During this reporting period, the conceptual Design Basis manual for the Plant Crist SCR Project was completed and released to DOE, EPRI, and the catalyst vendors for review. Meetings were held between SCS and Gulf Power to further define procurement and construction procedures and responsibilities. The following nine work packages were defined: piling and concrete; structural steel; mechanical; insulation; electrical; instrumentation and controls; painting; hoists; and control room. The base-line capital budget responsibilities were divided between SCS Engineering and Gulf Power.

The detailed design engineering phase continued during this reporting period. Vendor bids and technical responses were received, evaluated and contracts awarded for the distributed control system/data acquisition system, electrical distribution system, and bypass heat exchangers. Specifications were drafted and released for bids on the cyclones and flue gas/air electric heaters. Bid evaluations were completed and a contract awarded for the cyclones. Specifications for the service cooling water pumps, gas sampling and analyses systems, and the ammonia storage and handling system were developed. These specifications are undergoing review prior to release for vendor bids. Preparation of air compressor specifications was begun.

Design work continued on the control room, platforms, and ductwork. Based on comments received during a project review meeting with DOE and EPRI, the control room was enlarged by about $25 \%$ in floor space. Reactor design was begun and preliminary reactor design drawings were released for catalyst supplier review.

SCS compared and evaluated catalyst vendor responses to the previous quarter's request for information concerning important testing parameters for laboratory evaluation of SCR catalysts. Based on the results, SCS released for catalyst vendor review a list of proposed common laboratory test methods and conditions for all the catalyst suppliers to use for measuring results in this project. 
Although there were some exceptions taken to certain SCS proposals in the catalyst vendor comments received to date, for the most part there was consent with the majority of the SCS proposed conditions.

A preliminary test $\mathrm{pl}$ an and a Request for Proposal (RFP) for the testing services subcontractor were drafted. The RFP was released to six firms for bidding on the testing and analytical services required for the project.

DOE and SCS personnel visited the European catalyst suppliers during the last week of August. SCS held an engineering design review meeting with DOE and EPRI on September 6 . Project review meetings were held between SCS and Gulf Power on JuTy 17, and September 17 and 18. 
Section 2

INTRODUCTION

The Innovative Clean Coal Technology (ICCT) Program is designed to demonstrate clean coal technologies that are capable of retrofitting or repowering existing facilities to achieve significant reduction in sulfur dioxide $\left(\mathrm{SO}_{2}\right)$ and/or nitrogen oxides (NOX) emissions. The technologies selected for demonstration are capable of being commercialized in the 1990 s and are expected to be more cost effective than current technologies.

This ICCT project is jointly funded by the U.S. Departmeit of Energy, the Electric Power Research Institute (EPRI), and by Southern Company rvices (SCS) on behalf of the entire Southern electric system. The project's objective is to demonstrate the selective catalytic reduction (SCR) process that removes nitrogen oxides (NOX) from the flue gas of boilers that burn U.S. high-sulfur coal. The SCR technology involves the catalytic reduction of $\mathrm{NH}_{3}$ which is injected into the flue gas to react with NOx contained in the flue gas to produce molecular nitrogen $\left(\mathrm{N}_{2}\right)$ and water vapor.

A simplified SCR process flow diagram with major equipment is shown in Figure 1. Specifically, hot flue gas leaving the economizer section of the boiler is ducted to the SCR reactor. Prior to entering the reactor, $\mathrm{NH}_{3}$ is injected into the flue gas at a sufficient distance upstream of the reactor to provide for complete mixing of the $\mathrm{NH}_{3}$ and flue gas. The quantity of $\mathrm{NH}_{3}$ can be adjusted and it reacts with the $\mathrm{NO}_{x}$ from the flue gas. The flue gas leaving the catalytic reactor enters the air preheater where it transfers heat to the incoming combustion air. Provisions are made for ash removal from the bottom of the reactor since some fallout of fly ash is expected. Duct work is also provided to bypass some flue gas around the economizer during periods when the boiler is operating at reduced load. This is done to maintain the temperature of the flue gas entering the catalytic reactor at the proper reaction temperature of about $700^{\circ} \mathrm{F}$. The flue gas leaving the air preheater goes to the electrostatic precipitator (ESP) where fly ash is removed. The ESP is part of the existing plant and is generally unaffected by the SCR system except as higher SO, content affects the electrical resistivity of the fly ash or if $\mathrm{NH}_{4} \mathrm{HSO}_{4}$ co-precipitares with the fly ash. 
The SCR technology is in commercial use in Japan and western Europe on gas, oil, and on low-sulfur, coal-fired power plants. The first utility applications of SCR catalyst technology started in Japan in 1977 for 011 - and gas-fired boilers and subsequently in 1979 for coal-fired bollers. As of 1986, ninety utility boilers in Japan had been equipped with SCR catalyst technology including twenty-two coal-fired bollers. These coal-fired boilers represent a combined capacity in excess of 6500 MWe and are typically fired with a low-ash, low-sulfur coal.

In addition to Japanese experience, several countries in western Europe (most notably West Germany and Austria) have passed stringent $\mathrm{NO}_{\mathrm{x}}$ emission regulations that have all but mandated the installation of SCR. Prior to commercial SCR installations in West Germany, utility companies demonstrated several types of SCR facilities in prototype demonstration programs similar to this ICCT project. Over 50 SCR pilot plants were built and operated in western Europe. These pilot plants ranged from 19 to 6200 SCFM and provided the data base that led to rommercialization of the SCR technology in western Europe.

Previously comploted U.S. work with the SCR process on utility boilers consists of three projects which were carried out in the late 1970 s and early 1980s. One of these was carried out on a natural gas fired boiler by Southern California Edison. Another project consisted of a pilot test conducted for the EPA at Georgia Power's Plant Mitche11. This pilot plant treated a 1000 ACFM (0.5 MWe) slip stream of flue gas resulting from the combustion of lowto medium-sulfur coal. A third pilot-scale project, carried out at the Public Service Company of Colorado's Arapaho Station treated a 5000 ACFM (2.5 MNe) slip stream of flue gas resulting from the combustion of U.S. low-sulfur coal.

Although SCR is widely practiced in Japan and Europe, there are numerous technical uncertainties associated with applying SCR to U.S. coals. These uncertainties include:

(1) potential catalyst deactivation due to poisoning by trace metal species present in U.S. coals that are not present in other fuels. 
(2) performance of the technology and effects on the balance-of-planc equipment in the presence of high amounts of $\mathrm{SO}_{2}$ and $\mathrm{SO}_{3}$.

(3) performance of a wide variety of SCR catalyst compositions, geometries and methods of manufacture under typical high-sulfur coal-fired utility operating conditions.

These uncertainties will be explored by constructing a series of small-scale SCR reactors and simultaneously exposing different SCR catalysts to flue gas derived from the combustion of high sulfur IJ.S. coal.

The first uncertainty above will be handled by evaluating SCR catalyst performance for two years under realistic operating conditions found in U.S. pulverized coal utility boilers. The deactivation rates for the catalysts exposed to flue gas from high sulfur U.S. coal will be documented to determine accurate catalyst $1 \mathrm{ife}$, and thus, accurate process economics.

The second uncertainty above will be explored by performing parametric testing and through the installation/operation of air preheaters downstream of the larger reactors. During parametric testing, operating conditions will be adjusted above and below design values to observe deNOx performance and ammonia slip as functions of the change in operating conditions. Air preheater performance will be observed to evaluate effects from SCR operation upon heat transfer, and therefore, upon boiler efficiency.

The third uncertainty is being handled by using honeycomb- and plate-type SCR catalysts from U.S., Japan and Europe of various commercial composition. Results from the tests with these catalysts will expand our knowledge of performance on a variety of SCR catalysts under U.S. utility operating conditions with high-sulfur coal.

The intent of this project is to demonstrate comnercial catalyst performance, proper operating conditions, and catalyst life for the SCR process. This project will also demonstrate the technical and economic viability of SCR while reducing $\mathrm{NO}_{\mathrm{x}}$ emissions by at least $80 \%$.

The project will be conducted at Gulf Power Company's Plant Crist Unit 5, a commercially operating 75 MW unit, located in Pensacola, Florida, on U. S. coals with a sulfur content near $3.0 \%$. Unit 5 is a tangentially-fired, dry 
bottom boiler, with a hot and cold side ESPs for particulate control. The SCR process to be used in this demonstration will be designed to treat a slipstream of flue gas and will feature multiple reactors installed in parallel. With all reactors in operation, the maximum amount of combustion flue gas that can be treated is 17,400 standard cubic feet per minute (scfm) which is roughly equivalent to 8.7 MWe.

The proposed SCS facility is a slip-stream SC.R test facility consisting of three 2.5 MWe (5000SCFM) SCR reactors and six 0.20 MWe (400SCFM) reactors that will operate in parallel for side-by-side comparisons of commercially available SCR catalyst technologies obtained from vendors throughout the world. Figure 2 presents a simplified process flow diagram for the proposed facility. The large (2.5 MWe) SCR reactors will contain commercially available SCR catalysts as offered by SCR catalyst suppliers. These reactors will be coupled with small-scale air preheaters to evaluate the long-term effects of SCR reaction chemistry on air preheater deposit formation and the deposits' effects on air preheater. The small reactors will be used to test additional commercially available catalystis. This demonstration facility size will be adequate to develop performance data to evaluate SCR capabilities and costs that are applicable to boilers using high-sulfur U.S. coals.

The demonstration project is organized into three phases: (1) Phase I Permitting, Environmental Monitoring Plan and Preliminary Engineering; (2) Phase II - Detai1 Design Engineering and Construction; and (3) Phase III Operation, Testing, Disposition, and Final Report. The cooperative agreement was signed June 14, 1990, and the project completion date is now projected to be in the second quarter of 1995 . The total estimated project costs are $\$ 15,574,355$. The co-funders are $\operatorname{SCS}(\$ 6,049,017)$, DOE $(\$ 7,525,338)$, and EPRI $(\$ 2,000,000)$. 
Section 3

PROJECT DESCRIPTION

Within the three phases of the project, the following tasks will be conducted to effectively demonstrate the SCR process:

Phase I - Fermitting, Environmental Monitoring Plan and Preliminary Engineering

Task 1.1.1 - Prototype Plant Permitting Activities

Task 1.1.2 - Develop Environmental Monitoring Program

Task 1.1.3 - Preliminary Engineering

Task 1.1.4 - Engineering and Construction Contracts Scope Development

Task 1.1.5 - Project Management and Reporting

Phase II - Detail Design Engineering and Construction

Task 1.2.1 - Detailed Design Engineering

Task 1.2.2 - Construction

Task 1.2.3 - Operation Staff Training

Task 1.2.4 - Planning for Detailed Testing

Task 1.2.5 - Start-Up/Shakedown

Task 1.2.6 - Project Management and Reporting

Phase III - Operations, Testing, Disposition and Final Report

Task 1.3.1 - SCR Demonstration Facility Operations and Maintenance

Task 1.3.2 - Process Evaluation

Task 1.33 - Environmental Data Management and Reporting

Task 1.3.4 - Economic Evaluation

Task 1.3.5 - Dismantling/Disposition

Task 1.3.6 - Project, Management and Reporting 
Section 4

PROJECT STATUS

Progress during July-September, 1991, is summarized below for each of the ongoing tasks in the Scope of Work.

PHASE I - PERMITTING, ENVIRONMENTAL MONITORING PLAN AND PRELIMINARY ENGINEERING

\section{Iask 1.1.2 - Develop Environmental Monitoring Program}

Radian and SCS are addressing the issues previously raised by DOE's comments on the Environmental Monitoring P1an (EMP) in order to finalize the EMP.

\section{Task 1.1.3 - Preliminary Engineering}

The conceptual Design Basis manual for the Plant Crist SCR Project was completed and released to DOE, EPRI, and the catalyst vendors for review. The Design Basis included information on the following:

- Site characteristics

-Coal Analyses

-Ash Analyses

-Flue Gas Composition

- SCR Catalysts

- SCR Pllot Plant

- Layout

- Process Description

- Operational Philosophy

- Area Descriptions and Major Equipment

-Flue Gas Extraction Scoop to Flue Gas Distribution Header

-Flue Gas Distribution Header to Reactor Inlet

-Ammonia Storage to Reactors

-SCR Reactors

-SCR Reactor Outlet to Pilot Air Preheater Out let

-Cyclones to Host Boiler Duct

- Pilot Plant Air Compressor Station

-Gas Sampling System 
-Control Room

-Utility Systems

\section{Appendices}

-Equipment List

- Instrumentation Schedule

-Discussion of Ammonia and Ammonia Material Safety Data Sheet

-Safety Procedures

\section{Task 1.1.4 - Engineering and Construction Contracts Scope Development}

A meeting was held on July 17 between Gulf Power and SCS in which (a)procurement and construction procedures and responsibilities were further defined and (b) the process was begun to identify budget responsibility between SCS Engineering and Gulf Power Construction for individual base-1ine cost estimate items. The following nine work packages were defined: piling and concrete; structural steel; mechanical; insulatior; electrical; instrumentation and controls; painting; holsts; and control room. Further review continued through August and September and a meeting was held with Gulf Power on September 17 to complete discussions on splitting the base-line capital budget responsibilities between Gulf Power and SCS Engineering. Based on the results of this meeting, the budget responsibilities will be sorted by both (a)work packages for Gulf Power and (b)project tasks for SCS Engineering.

PHASE II - DETAIL DESIGN ENGINEERING AND CONSTRUCTION

\section{Task 1.2.1 - Detailed Design Engineering}

The detailed design engineering phase continued during this reporting period. Vendor bids and technical responses on the specifications for the distributed control system/data acquisition system, electrical distribution system, and bypass heat exchangers were received, evaluated and contracts awarded. Specifications were completed for the cyclones and flue gas/air electric heaters and released for bids. Bid evaluations were completed and a contract awarded for the cyclones. Electric heater bid evaluations were underway at the end of September. The list of major equipment contracts awarded and the selected vendors are as follows: 
Heat Pipe Air Preheater

Rotary Air Preheater

Flue Gas/Air Fans

Gas Flow Venturis

$480 \mathrm{~V}$ Motor Control Center

4KV Switchgear

Miscellaneous Transformers

Distributed Control/Data Acq. System

Fly Ash Cyciones

Bypass Heat Exchangers
$A B B$ Air Preheater

ABB Air Preheater

Howden Sirocco

Flow-1 in Corp.

Southern Engineering

Siemens Energy

ABB Power T/D

Bailey Controls

Fisher-Klosterman

Xchanger, Inc.

Specifications were developed during this reporting period for the service cooling water pumps, gas sampling and analyses systems, and the ammonia storage and handling system. These specifications are undergoing review prior to release for vendor bids. Preparation of specifications for the air compressor was also begun.

Design work continued on the control room, platforms, anu ductwork. Pased on comments received during a September 6 project review meeting svith DOE and EPRI, the control room was enlarged by about $25 \%$ in floor space. (See Appendix A for latest control room drawing.) The ductwork arrangement also had to be revised to avoid existing equipment and the latest routing is shown in drawings included in Appendix $B$.

Reactor design was begun and a visit was made to Plant Miller, near Birmingham, Alabama, to see a pilot-scale reactor containing oxidation catalyst for converting $\mathrm{SO}_{2}$ to $\mathrm{SO3}$. Preliminary reactor design drawings (large and small reactors) were drafted and released for review by the catalyst suppliers.

The catalyst vendors responded to an earlier request from SCS on information concerning important testing parameters for laboratory evaluation of SCR catalysts. SCS compared and evaluated the responses during July and August, and in late August SCS raleased for catalyst vendor review the proposed common laboratory test methods and conditions for all the catalyst suppliers to use for measuring results in this project. A few of the vendors had responded with comments by the end of September, and although there were exceptions taken to some of the proposed conditions, for the most part there was consent 
with most of the SCS proposed conditions. After review of the responses from a1) the catalyst vendors, SCS will submit a revized set of proposed conditions for further review and approval. In addition to the laboratory procedures, cata'vst suppliers were asked to review reactor design drawings and provide comments on catalyst sampling and loading/unloading criteria. Review of the responses received to date was begun.

A preliminary test $\mathrm{plan}$ and a Request for Proposal (RFP) for thie testing services subcontractor were drafted. After consultation with DOE and EPRI, SCS released the RFP to six firms for bidding on the testing and analytical services required for the project. Bid responses are due by November 15 . A copy of the released RFP is enclosed in Appendix $C$.

\section{Iask 1.2.6-Project Management and Reporting}

Weekly coordination meetings were held with Design Engineering. The MIS, developed for tracking overall budget and schedule information, was used to monitor budget and schedule and to help fulfill DOE reporting requirements. Monthly progress reports were submitted to DOE. A brief status progress summary was prepared and released to each of the catalyst suppliers.

DOE and SCS personnel visited the European catalyst suppliers during the last week of August. SCS held an engineering design review meeting with DOE and EPRI on September 6 . Project review meetings were held between SCS and Gulf Power on July 17, and September 17 and 18. 
Section 5

PLANNEU ACTIVITIES

During the October - December, 1991 quarter, the following activities are planned:

- Complete the following portions of Phase II, detailed engineering design:

1. Complete evaluations of vendor bid responses and award contracts for flue gas and air electric heaters.

2. Develop specifications, issue inquiries for vendor bids, complete evaluations of vendor bid packages, and award contract for the ammonia storage system, gas sampling system, air compressor, and other minor equipment such as sootblowers, control/isolation dampers, and service cooling water pumps.

3. Incorporate received comments into reactor design and develop final specifications and issue inquiry for vendor bids on reactor vessels.

4. Finalize specifications and issue bid inquiries for the following: concrete and pilings; structural steel; ductwork and reactor transition ductwork; fly ash handling; fire protection system; and personnel and catalyst hoist.

- Receive and evaluate vendor bids on RFP for testing and analytical services and make vendor selection.

- Revise proposed common laboratory testing procedures and submit for further catalyst supplier review.

- Visit Japanese catalyst suppliers. 
APPENDIX A

Control Building Floor Plan 
APPENDIX B

SCR Pilot Plant

Ductwork Extraction Sketches





















\section{APPENDIX C}

Request for Proposal

for Testing and Analytical Services
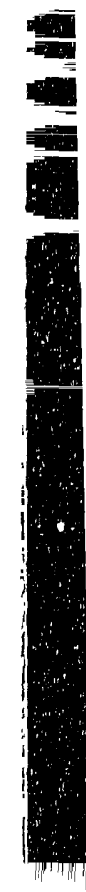


\title{
INNOVATIVE CLEAN COAL TECHNOLOGY DEMONSTRATION OF SELECTIVE CATALYTIC REDUCTION TECHNOLOGY FOR THE CONTROL OF NITROGEN OXIDE (NOX) EMISSIONS FROM HIGH-SULFUR COAL-FIRED BOILERS
}

\author{
REQUEST FOR PROPOSAL FOR TESTING AND ANALXTICAL SERVICES
}

\section{INTRODUCTION}

The U. S. Department of Energy's (DOE) Innovative Clean Coal Technology (ICCT) Program is designed to demonstrate clean coal technologies that are capable of retrofitting or repowering existing facilities to achleve significant reduction in sulfur dioxide $\left(\mathrm{SO}_{2}\right)$ and/or nitrogen oxides (NOx) emissions. The technologies selected for demonstration are capable of being commercialized in the 1990s and are expected to be more cost effective than current technologies. In October of 1988, So'dthern Company Services, Inc. (SCS) was selected by DOE to demonstrate selective catalytic reduction (SCR) technology at pilot scale to reduce NOx emissions from a high-sulfur, coal-fired boiler.

This ICCT project is jointly funded by the DOE, the Electric Power Research Institute (EPRI), and SCS (on behalf of the entire Southern electric system). The project's primary objective is to demonstrate that commercially available SCR catalysts can successfully remove NOx from the flue gas of boilers that burn U.S. high-sulfur coal without premature deactivation and without significant operational problems.

A simplified, generic SCR process flow diagram with major equipment is shown in Figure 1. Specifically, hot flue gas leaving the economizer section of the botler is ducted to the SCR reactor. Prior to entering the reactor $\mathrm{NH}_{3}$ is injected into the flue gits at at sufficient distance upstream of the reactor to provide for complete mixing of the $\mathrm{N} H$, and the gas. The quantity of injected $\mathrm{NH}_{3}$ is controlled in proportion to the $\mathrm{NO}$. concentration in the flue gas. The flue gas leaving the catalitic reactor enters the atr preheater where it transfers heat to the incoming combustion air. Provisions are made for asth removal from the bottom of the reactor since some fallout of fly ast is cxpected. Duct work is also provided to bypass some the gas around the economizer during periods when the boiler is operating at reduced load. This is done 10 maintain the temperature of the flue gas entering the catalytic reactor at the proper reaction temperature of about $700^{\circ} \mathrm{F}$. The flue gas leaving the air preheater goes to the electrostatic precipitator (ESP) where fly ash is removed. The ESP is part of the existing plant and is generally unaffected by the SCR system except as higher SO ${ }_{3}$ content alfects the electrical resistivity of the fly ash or if ammonia bisulfate (NI, HSO $)_{4}$ co-precipitalcis with the tly ash.

SCR technology is in commercial use in Japan and western Europe on gas, oil, and on low-sulfur, coal-fired power plants. The first utility applications of SCR caltalyst technology started in Japan in 1977 for oil- and gis-fired boilers and subsequenty in 


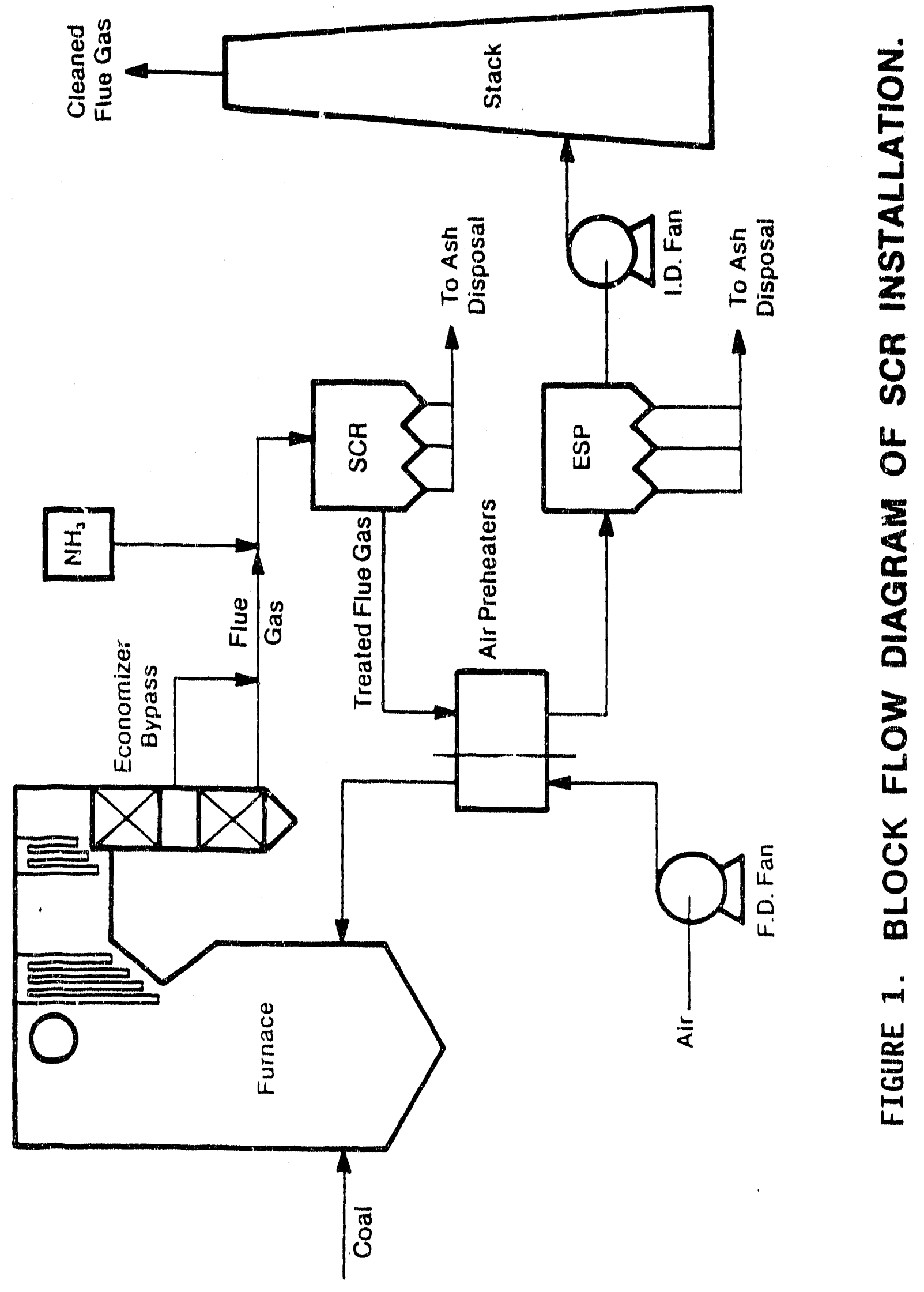


1979 for coal-fired boilers. There are SCR systems installed at over 36,000 MW of fossil fuel-fired electricity generation capacity in Japan. The SCR process is used on about $6,200 \mathrm{MW}$ of coal-fired boilers, which is about 54 percent of the total coal-fired capacity. In addition to Japanese experience, several countries in western Europe (most notably West Germany and Austria) have passed stringent $\mathrm{NO}_{\mathrm{x}}$ emission regulations that have all but mandated the installation of SCR. There is abo'tt 33,000 MW of SCR capacity on fossil fuel-fired utility boilers in Europe. About $30,500 \mathrm{MW}$ are on coal with the rest on gas and oll. The above-mentioned Japanese and Western Europe SCR experience for coal-fired boilers is entirely with low-sulfur coal (l.e. $<1.5 \%$ sulfur).

Although there have been brief pilot-scale tests of SCR performed in the U.S., and there is now a series of pilot plant studies in progress under EPRI funding and management, questions remain regarding application to U.S. coals with high-sulfur and different trace metal composition. The technical uncertainties associated with applying SCR to U.S. coals include:

(1) potential catalyst deactivation due to poisoning by trace metal species present in U.S. coals that are not present in other fuels.

(2) performance of the technology and effects on the balance-of-plant equipment in the presence of high amounts of $\mathrm{SO}_{2}$ and $\mathrm{SO}_{3}$.

performance of a wide variety of SCR catalyst compositions, geometries and methods of manufacture under typical high-sulfur coal-fired utility operating conditions.

These uncertainties will be explored in the SCR/DOE ICCT project by constructing a series of small-scale SCR reactors and simultaneously exposing different SCR caltalysts to the gals derived from the combustion of high sulfur U.S. coal.

The tirst uncertainty above will be handled by evaluating SCR catalyst performance for two years under realistic operating conditions found in U.S. pulverized coal utility boilers. The deactivation rates for the satalysts cxposed to flue gas from high sulfur U.S. coal will he documented to determine accurate catalyst life, and thus, accurate process economics.

The second uncertainty above will be explored by performing parametric testing and through the installation and operation of air preheaters downstream of some of the larger pilot-scale reactors. During parametric testing, operating conditions will be adjusted above and below design values to observe deNOx performance and ammoniat slip as functions of the change in operating conditions. Air preheater performance will be observed to evaluate effects from SCR operation upon heat transter, and therefore. upon boiler efficiency.

The third uncertainty is being handled by using honeycomb- and plate-type SCR catalysts from U.S., Japan and Europe of various commercial compositions. Results from the tests with these catalysts will expand the existing knowledge of performance of a variety 
of SCR catalysts under U.S. utility operating conditions with high-sulfur coal.

The intent of this project is to demonstrate commercial catalyst performance, proper operating conditions, and catalyst life for the SCR process. This project will also demonstrate the technical and economic viability of SCR while reducing $\mathrm{NO}_{x}$ emissions by at least 80 percent.

The project will be conducted at Gulf Power Company's Plant Crist Unit 5, a commercially operating $75 \mathrm{MW}$ unit, located in Pensacola, Florida, on U. S. coals with a sulfur content near $3.0 \%$. Unit 5 is a tangentially-fired, dry bottom boiler, with a hot and cold side ESPs for particulate control. The SCR process to be used in this demonstration will be designed to treat a slip-stream of flue gas from Unit 5 and will feature multiple reactors installed in parallel. With all reactors in operation, the maximum amount of combustion flue gas that can be treated is 17,400 standard cubic feet per minute $(\mathrm{scfm})$ which is roughly equivalent to $8.7 \mathrm{MWe}$.

The proposed SCS facility is a slip-stream SCR test facility consisting of three $2.5 \mathrm{MWe}$ (5000SCFM) SCR reactors and six $0.20 \mathrm{MWe}$ (400SCFM) reactors that will operate in parallel for side-by-side comparisons of commercially available SCR catalyst technologies obtained from vendors throughout the world. Figure 2 presents a simplified process flow diagram for the proposed facility. The large $(2.5 \mathrm{MWe}) \mathrm{SCR}$ reactors will contain commercially available SCR catalysts as offered by SCR catalyst suppliers. These reactors will be coupled with small-scale air preheaters to evaluate the long-term effects of SCR reaction chemistry on air preheater deposit formation and the deposits' effects on air preheater. The small reactors will be used to test additional commercially available catalysts. This demonstration facility size will be adequate to develop performance data to evaluate SCR capabilities and costs that are applicable to boilers using high-sulfur U.S. coals. A more detailed description of the SCR pilot plant is given in Attachment $\mathrm{A}$.

The demonstration project is organized into three phases: (1) Phase I - Permitting, Environmental Monitoring Plan and Preliminary Engineering; (completed) (2) Phase II . Detail Design Engineering and Construction; (on-going) and (3) Plase III - Operation. Testing, Disposition, and Final Report (planned). A Cooperative Agreement between SCS and DOE was signed June 14, 1990, and the project completion date is now projected to be in the second quarter of 1995 .

A simplified version of the current project schedule is shown in Figure 3. Detuiled design engineering is now in progress. Construction is scheduled to begin in January 1992. Pilot plant start-up/shakedown is to occur from November 1992 through January 1993. The process testing and evaluation commences near the end of January 1993 and lasts for two years. The project should be concluded by the end of May 1995.

\section{PROJECT ORGANIZATION DURING OPERATIONS}

The organization of the operation, maintenance, and testing activities for this demonstration project is shown in Figure 4. 


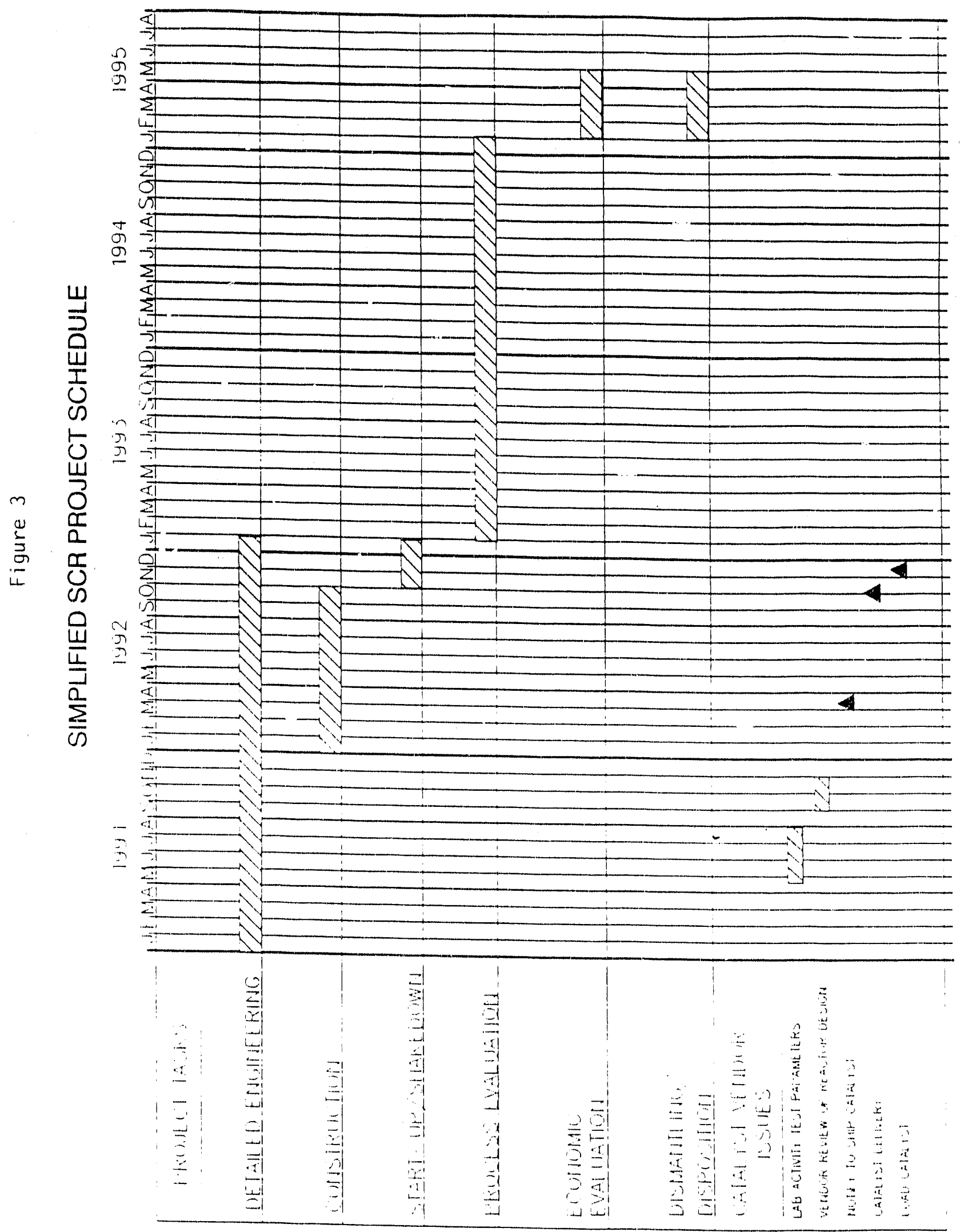




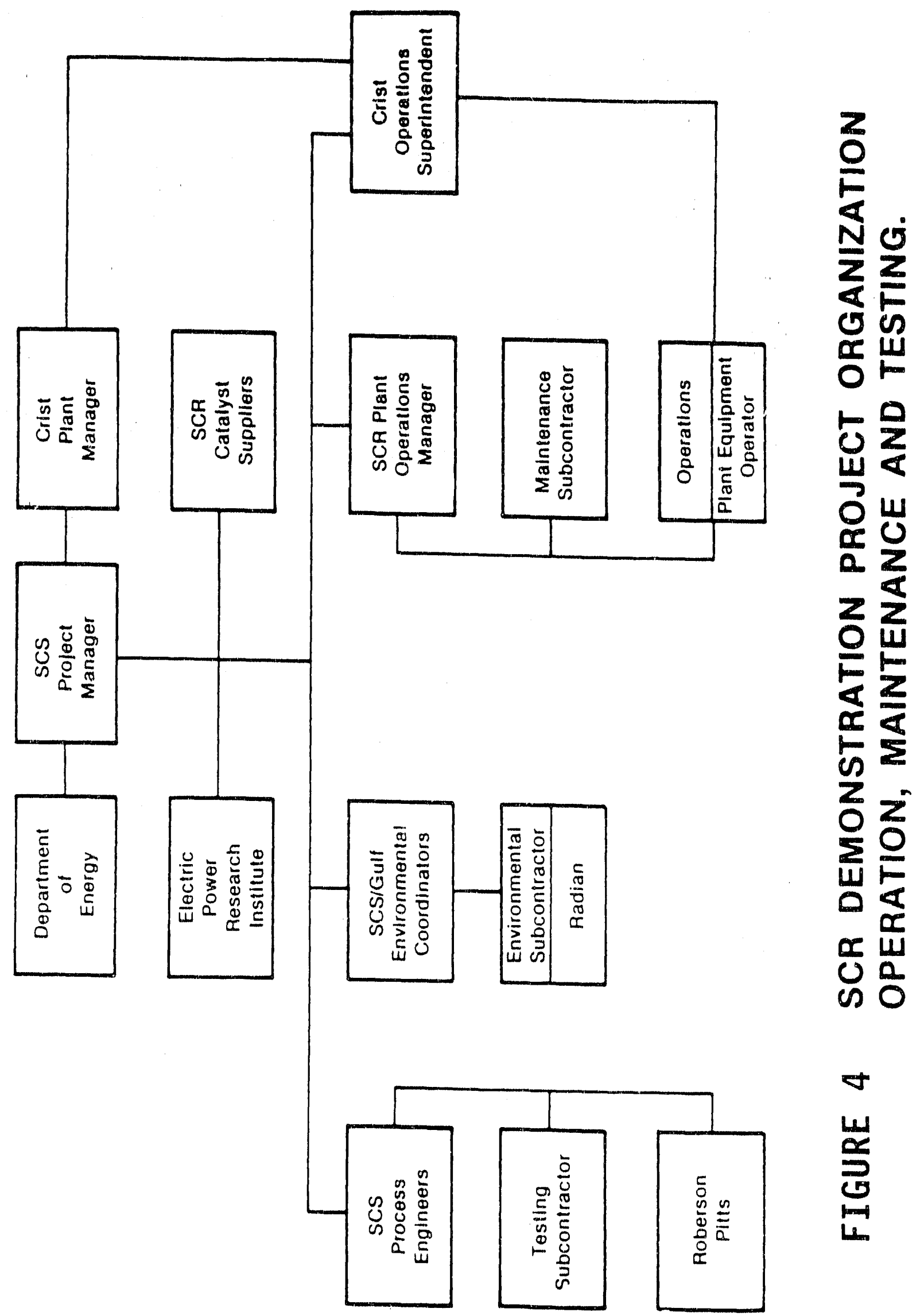


The Project Manager for the DOE ICCT Demonstration Project at Plant Crist is Mr. Doug Maxwell of Southern Company Services (SCS), who has overall responsibility for execution of the program. The Project Manager directs SCS and Gulf Power Company personnel to perform various duties related to site coordination, design engineering, environmental matters, and cost coordination. During the operational phase of this project, the Project Manager will continue to direct the overall project, but will focus on coordinating the testing needs of all parties to the program, including the DOE, EPRI, SCR vendors and SCS technical staff. He will rely on SCS Process Engineering staff for analysis of process data and on the SCR Operations Manager to maintain the SCR facility in good operating order. He will have final responsibility for producing a thorough evaluation of each catalyst selected for participation in the program and will have final authority over process operations.

Operation of the SCR facility will be carried out by a dedicated orl-site operations staff. The SCR facility operations, maintenance and testing staff will consist of:

- Operations personnel drawn from the regular Plant Crist operations staff. These personnel will be dedicated to pilot-plant operations and will receive training in operations of the plant prior to start-up.

- Maintenance personnel consisting of full-time instrument technicians and a machinist hired as needed from a maintenance subcontractor (to be seiected). It is anticipated that two instrument technicians will be required due to the large number of analytical and process control instrumentation in the operations of the pilot-plant. It is intended that these instrument technicians will provide frequent calibration and span checks to assure the accuracy of the collected data. As such, these tasks are not a part of the testing contractor's scope of work.

- The testing subcontractor will provide full-time analytical chemists whose duties will be:

- conducting routine wet chemical flue gas analysis for $\mathrm{SO}_{3}$ and $\mathrm{NH}_{3}$ (with periodic $\mathrm{HCl}$ and $\mathrm{N}_{2} \mathrm{O}$ measurements) for both large and small SCR reactors

- collecting periodic flyash samples as part of long-term air prehoater monitoring studies

- collecting non-routine samples (i.e. Air preheater water wash, APH deposits, catalyst samples

- The testing subcontractor will also provide for an on-site laboratory (laboratory space to be provided) capable of ion chromatograply, gats chromatography, $\mathrm{pH}$ analysis, colorimeter and gas and particulate sampling equipment. The importance of $\mathrm{SO}_{3}$ and slip $\mathrm{NH}_{3}$ data and the instability of wet chemical samples makes on-site determination of these values necessary. Continuous, 24-hour per day operation of 9 reactors implies the need for more than one analytical chemist to keep up with the sample load. 
- One on-site Process Engineer. The data production rate from the operating prototype facility will be high, in terms of both operational data (temperatures, pressures, flowrates, etc.) as well as analytical data. Moreover, rapid data reduction is required in order to make decisions regarding test data accuracy, length of testing, changes in day-to-day test operations, etc. The on-site process engineer will have responsibility for a testing and data analysis at Plant Crist site, will coordinate all testing activites and be responsible for assimilating and reporting the results of the pilot facility. The on-site process engineer will have day-to-day authority over the testing subcontractor who will provide manual data collection to supplement autoniated data. He will report directly to the Project Manager.

- One on-site pilot-plant Operations Manager. This person will be responsible for all aspects of the operations and maintenance of the SCR pilot-plant. In addition he will provide liaison between the SCR pilot-plant and other Plant Crist operating groups. The operations manager will be required to keep the prototype SCR facility on-line producing valid test data. He will be responsible for the performance of the operating staff and maintenance personnel assigned to the pilot facility.

There will be other personnel involved in the pilot-plant demonstration program. However, the personnel mentioned above will be primarily responsible for keeping the pilot-plant in daily operation.

\section{TESTING SUBCONTRACTOR - STATEMENT OF WORK}

The scope of this program is for the testing subcontractor to provide testing support and analytical services for the SCR pilot plant project. The testing subcontractor will provide:

- a qualified staff of test personnel to visit the site prior to and during startup to provide documentation of existing flue gas conditions on Plant Crist Unit 5 as well as validation of the SCR pilot plant design.

- During pilot plant operation, the testing subcontractor will also provide onsite personnel to perform manual $\mathrm{NH}_{3}$ and $\mathrm{SO}_{3}$ measurements, collect periodic gasaous emission data for other gases such as $\mathrm{HCl}, \mathrm{N}, \mathrm{O}$, etc. and collect periodic particulate samples from various process locations. These personnel will report to an on-site Process Engineer for day-to-day technical guidance. They will also report administratively to appropriate home office management within their own organization. The testing subcontractor's home office management will report directly to the Project Manager.

The tasks to be performed by the testing subcontractor are listed below and described in more detail. 
Task 1-Commissioning Without Catalyst and Without Ammonia Injection

The flue gas slipstream extraction scoop and pilot-plant ductwork system will be tested to assure that the characteristics of particulates in the flue gas entering the pilot SCR reactors are the same as in the main power plant ductwork gas stream and are not biased in terms of particle size distribution or mass loading due to slipstream extraction. In addition, the SCR facility will be started up prior to completion of construction to allow components in the flue gas (both solid and gaseous materials) to equilibrate with the fresh ductwork to minimize any possible detrimental effects on the flue gas entering the reactors at the initiation of testing. Analytical support to this subtask for flue gas composition and particulate measurements will be provided as part of the testing subcontractor's scope of work.

Th: as sampling system will be calibrated using certified span gases to test for both gas analyzer accuracy and sample line integrity. Support to this subtask will be provided by the supplier of the analysis system.

Baseline wet chemical measurements of all flue gas components will be made during this subtask by the testing subcontractor as support to gas sampling system start-up and calibration.

During start-up of the SCR reactors an extensive program to measure the performance of the flue gas extraction system is planned as shown in Table 1. This performance measurement will include:

- Total particulate mass loading, particulate size distributions and flue gas velocity profiles at the location of the flue gas extraction scoop in each main power plant duct (i.e. two locations) to establish base-line particulate and gas tlow conditions. Similar measurements will be taken at the hotside ESP outlet to establish any impact on plant from tlue gas extraction scoop.

- Similar measurements at the SCR reactor flue gas supply duct manifold (prior to SCR reactor drawoffs) to adequately document that the extraction scoop and gas supply ducts are not biasing the particulate and gas sample reaching the SCR reactor system.

(See Figures 2.3-1 through 2.3-8 in attachment $\mathrm{A}$, showing the layout drawings, and Figures 5 and 6 on the following pages which show sketches of extraction scoop and reactor drawoffs.) 
Table 1

\section{START-UP TESTING AND MEASUREMENT}

MEASUREMENTS

Particulate: (at high and low load)

- loading

- size distribution

- composition

Flue gas velocity and temperature profiles, and duct static pressure as function of load.

Concentrations of $\mathrm{NO}, \mathrm{NO}_{x}$ and $\mathrm{O}_{2}$

Other analyses:

$\mathrm{NH}_{3}, \mathrm{~N}_{2} \mathrm{O}, \mathrm{SO}_{3}$

Concentrations of trace metals

(e.g. As, $\mathrm{Hg}, \mathrm{Pb}, \mathrm{Cd}$ )

\section{DESCRIPTION}

Extensive characterization during start-up.

Test each power plant duct after construction.

Test pilot plant extraction scoop.

Test inlet to each SCR reactor during start-up.

Extensive mapping of main power plant ductwork, extraction scoop, and reactor inlet during start-up.

Initial calibration of venturi flowmeters.

Characterization across plant duct, extraction scoop, inlet to each SCR reactor during start-up.

Calibrate continuous analyzers (if used).

Concentrations in gaseous phase and in fly ash at extraction scoop and each SCR reactor inlet during start-up. 


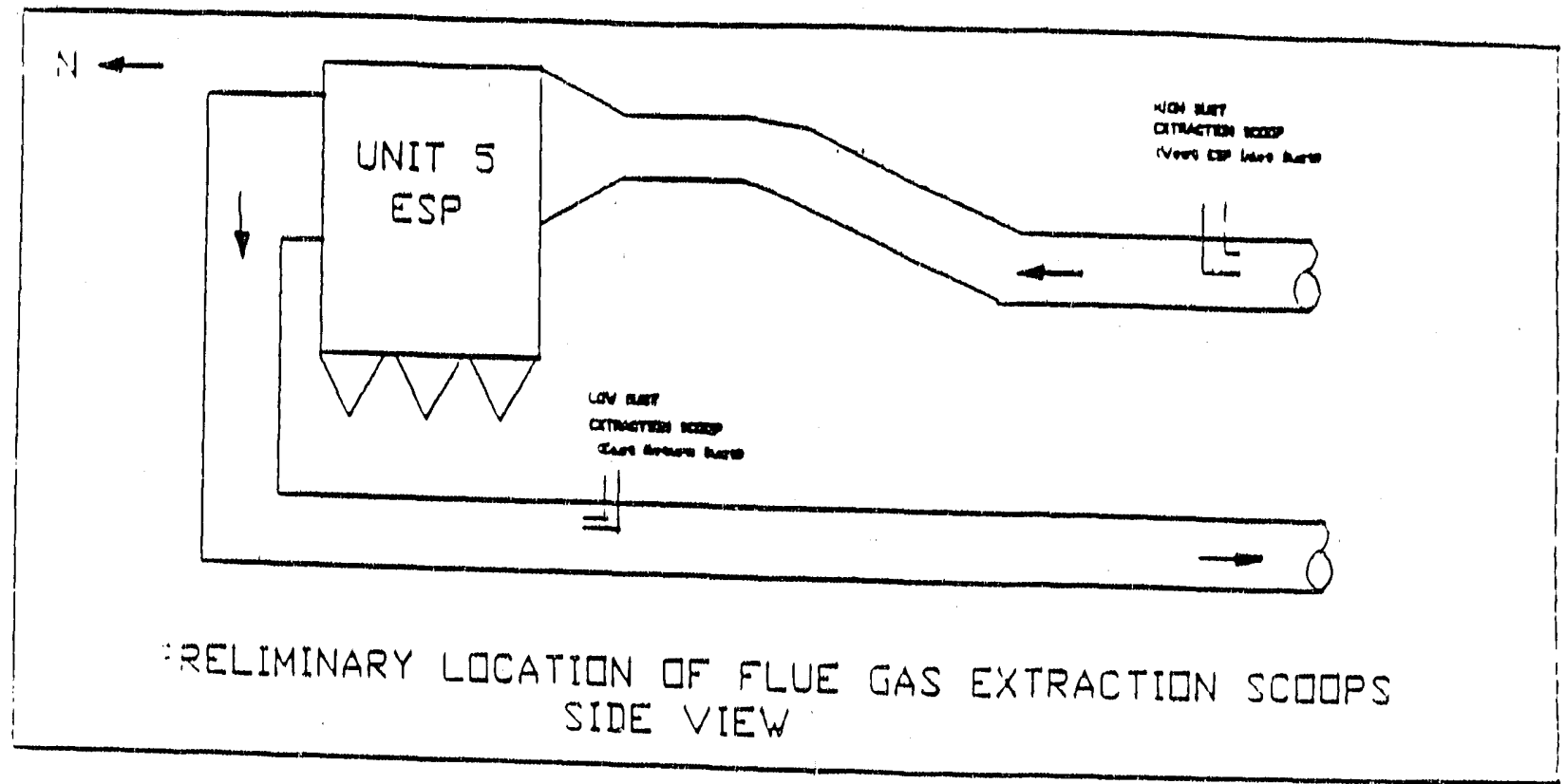

a. Side view.
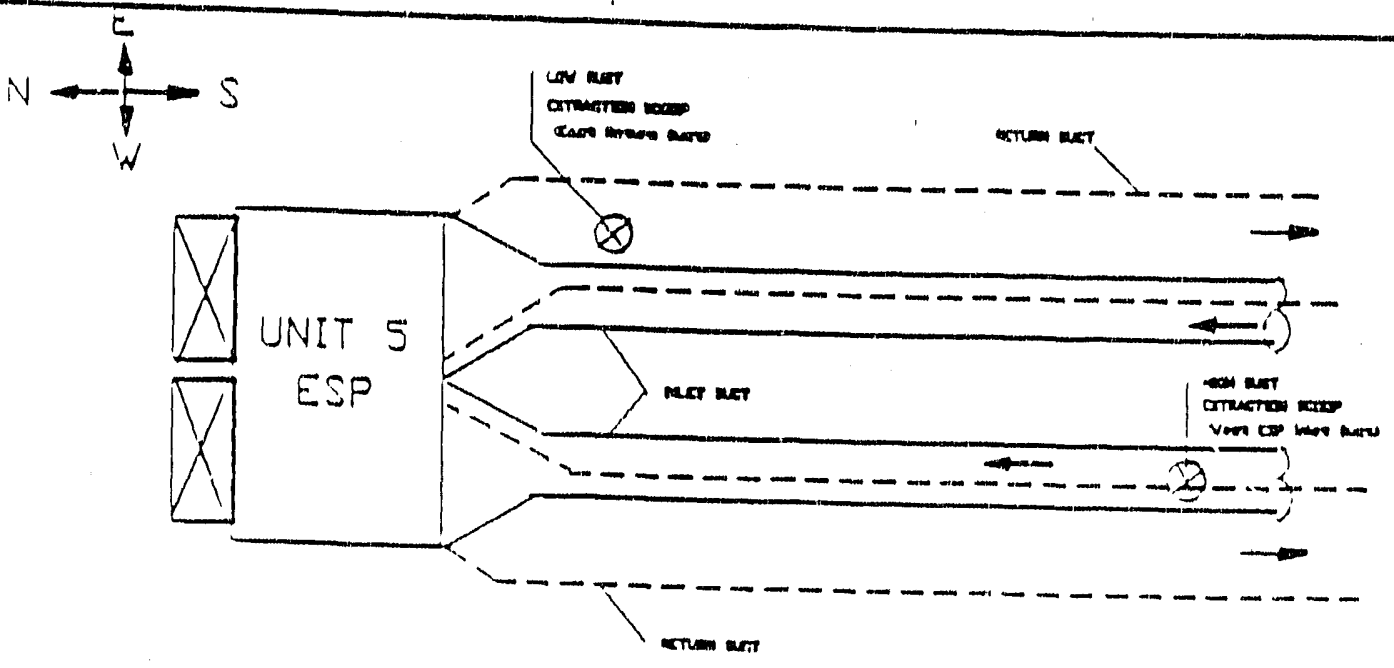

FPELIMINARY LOCATION OF FLUE GAS EXTRACTICN SEOEPS

b. Top view.

Figure 5 Preliminary location of flue gas extraction scoops. 


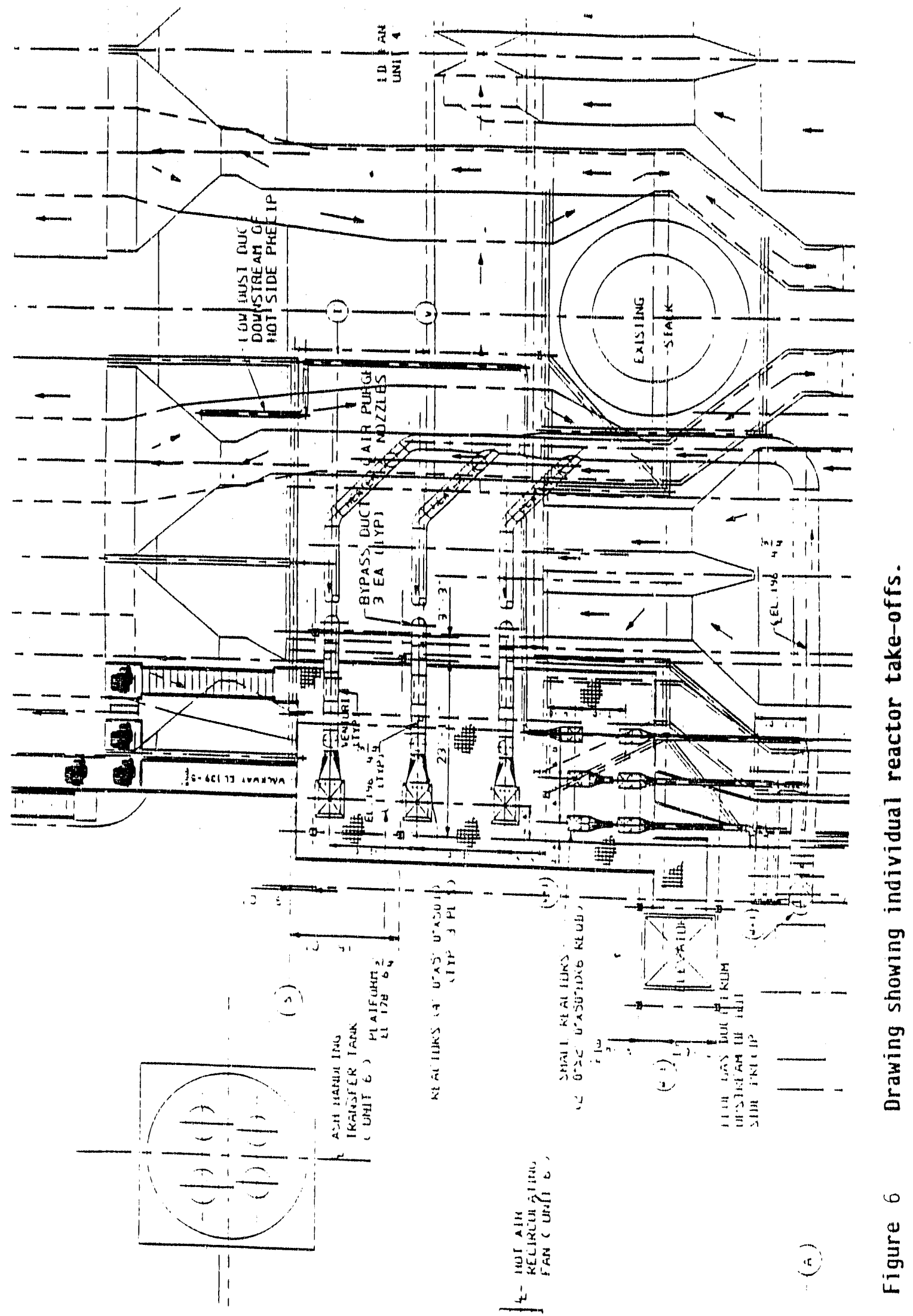


- Similar measurements at the inlet to each SCR reactor to verify that the reactor supply manifold and Inlet ductwork are not adversely affecting the gas of solids species entering each reactor. Also at this point, the venturis measuring gas flows to the reactor will be calibrated with pilot traverses.

These particulate measurements will include total mass concentrations, particle size distributions and chemical analysis of the size fractionated particulate samples. These extensive measurements are being performed since one of the major deactivation mechanisms for SCR catalyst when applled to high-sulfur coal is expected to be caused by particulate. Particulate deactivation may result from:

- fine particulate Infiltrating and plugging catalyst pores thereby decreasing the reactive surface area avallable for de $\mathrm{NO}_{x}$ reactions.

- reactions of flyash components (either metals or gaseous species) with the vanadium, tungsten, titanium or other trace metals on the catalyst surface.

- deposition via condensation of vapor-phase metallic components originating with the coal flyash on the catalyst surface that would otherwise conclense and deposit on the flyash.

For these reasons it is important to adequately document the quantity, size distribution and chemical composition of the particles reaching the catalyst and assure that use of a slipstream facility does not bias the particulate characteristics in any way.

The testing contractor should propose sampling and analytical methodologies to obtain the following data for particulates:

- Total mass loading - Typical test methods: EPA Test Method 17 or Method 5. Testing contractor should propose and describe preferred method. The method must provide for samples to be taken uniformly across duct cross-sections to assure that flue gas flow distributions are properly accounted for. The proposed method must be compatible with flue gas temperature conditions as high as $700^{\circ} \mathrm{F}$.

- $\quad$ Particle size distribution - Typical methods include cyclone and calsciade impactors. Testing contractor should propose methods for sampling both high and low dust locations. It is desirable to collect relatively large quantities of size segregated samples in order to provide for subsequent chemical analysis by size category.

- Chemical measurements of size fractionated samples - Typical measurement techniques include atomic absorption spectroscopy (AA), Instrumental Neutron Activation Analysis (INAA) or Inductively Coupled Argon Plasma (ICAP) atomic emission spectroscopy. The testing contractor should propose these or equivalent techniques for the data required at Plant Crist. 
- On-line tracking of changes in particle size distribution - As un option, the testing contractor may propose techniques for combining the above baseline information with on-line analytical measurements to provide qualitative tracking of changes in particulate characteristics.

In addition to particulate measurements during start-up, the testing contractor should propose techniques for the following measurements:

- Baseline measurements of $\mathrm{HCl}, \mathrm{NH}_{3}, \mathrm{SO}_{3}$ and $\mathrm{N}_{2} \mathrm{O}$ in the Unit 5 flue gas as well as predicted opacity.

- $\quad$ Flue gas velocity and temperature profiles, and duct static pressures. These will be mapped for main power plant ductwork, extractlon scoop and each SCR reactor inlet during startwup. Initial calibration of venturi flowrneters.

- Concentrations of $\mathrm{NO}, \mathrm{NOx}$, and $\mathrm{O}_{2}$ will be characterized across the plant duct, extraction scoop, and inlet to each reactor during start-up.

- Measurements of concentrations in the gass-phase and on the flyash of trace metals (such as $\mathrm{As}, \mathrm{Hg}, \mathrm{Pb}$, and $\mathrm{Cd}$ ) should be sampled simultaneously at the extraction scoop and each reactor inlet.

- Determination of flue gas $\mathrm{SO}_{2}$ and $\mathrm{SO}_{3}$ concentration before and after each electric heater.

For the above measurements, (except trace metal concentrations) the duct averages, standard deviation, and coefficlent of variation will be reported. It is requested that the testing subcontractor propose the methods for conducting these measurements and the number of measurements needed to provide reliable results. Eich of these measurements will need to be conducted for a low and high load level for Plant Crist Unit 5. A report will be prepared by the testing subcontractor and delivered to SCS which summarizes the results of this testing.

SCS will retain responsibility for the following:

- Initial calibration of all gals sampling system monitors (using cortilied spatn gases).

- Baseline flue gas composition via gals sampling system (to include O., ('O)." $\left.\mathrm{CO}, \mathrm{NOx}, \mathrm{SO}_{2}\right)$.

As such, these measurements are not part of the testing contractor's scope of work. However, the testing contractor will assist in verifying that the gals sampling system is providing representative data by the characterization of flue gats composition $\quad \mathrm{O}_{2,} \mathrm{CO}_{2}$ $\mathrm{CO}, \mathrm{NO}_{1}, \mathrm{SO}_{2}$ ) at each gas sampling point. (See Attachment B.)

For non-routine gaseous analysis (i.e. for $\mathrm{NH}_{3}, \mathrm{SO}_{3}, \mathrm{HCl}$ or $\mathrm{N}_{2} \mathrm{O}$ ) manual gas sampling and analyses using standard wet chemical methods may be used. The contractor should propose and describe sampling methods for: 
- $\quad \mathrm{NH}_{3}$ - Ammonia measurements will be critical to the success of the entire demonstration program, given the importance of slip $\mathrm{NH}_{3}$ to SCR process efficlency and to minimize negative impacts of the technology. It is expected that $\mathrm{NH}_{3}$ sllp will be present in the flue gas at concentrations ranging from 0 to $40 \mathrm{ppm}$, with typical concentrations between 0 and 5 $\mathrm{ppm}$. The contractor must propose techniques to accurately measure $\mathrm{NH}_{3}$ in these ranges in the presence of particulate-laden gas and in the presence of substantial $\mathrm{SO}_{3}$. SCS is aware that past studies of slip $\mathrm{NH}_{3}$ have attempted continuous measurement of $\mathrm{NH}_{3}$ by use of a $\mathrm{NOx}$ monitor with $\mathrm{NH}_{3}$ oxidation to NOx. However, it is our opinion that this tectnicque is not precise enough to distinguish between unreacted NOx and NOx due to slip $\mathrm{NH}_{3}$ oxidation. Testing contractor may propose continuous methods of $\mathrm{NH}_{3}$ measurements, but must address issues of accuracy, precision and reproducibility. A description of continuous $\mathrm{NH}_{3}$ measurement methodology should also be provided. In addition, techniques should be proposed for analysis of $\mathrm{NH}_{3}$ on tlyash, since this measurement will be used for material balance closure - see item (1) under Task 2.

- $\mathrm{SO}_{3}$ - Equally important to the $\mathrm{NH}_{3}$ are the levels of $\mathrm{SO}_{3}$ in the flue gas; both $\mathrm{SO}_{3}$ generated by the combustion process and converted from $\mathrm{SO}_{2}$ due to oxidation across the electric heater and on the SCR catalyst. SCS expects buseline $\mathrm{SO}_{3}$ concentrations in the 5 to 15 pprin range with $\mathrm{SO}_{3}$ at SCR system outlet to be as high as $40 \mathrm{ppm}$ under some conditions.

- $\quad \mathrm{HCl}$ - This acid gas will be measured to document the major sources of halogens that could interface with deNOx reaction on the cattalyst surfince. The chlorine content of Plant Crist coal is typical of bituminous coal ( 1),2 to $0.5 \%)$

- $\quad V_{2} \mathrm{O}$ - This gas will be measured on a screening basis, initially to document that partial reduction of NOx is not occurring. Subsequent measurements will be based on initial screening results.

SCS solicits in each response to this RFP, a list of proposed methods for the above tand all other measurements to be made by the testing subcontractor) and justificition warrunting use of such a method in this SCR pilot plant project.

Other measurement activities outside of the testing subcontractor scope will include checkout of all temperature and pressure sensing instrumentation and flow metering equipment (for steam, electricity and injected $\mathrm{NH}_{3}$ flows) ard checkout of computer controlled sample sequencing logic, process data signal generation, reading, transmission and telecommunication. $\mathrm{O}_{2}$ concentration across the pilot plant system will be checked and necessary corrections made to reduce air in-leakinge. As such, these activities shuuld not be proposed by testing contractor. However, this data will be available to the contractor for measurement purposes. 


\section{Task 2. Commissioning Without Catalyst and with Ammonia Injection}

The testing subcontractor will assist in verifying ammonia flow control, establishing an ammonia mass balance and measuring ammonia oxidation across the reactors prior to loading catalyst into the reactors. It is recommended that the following tests be performed during start-up:

1) Monitor anmonia in gas and or flyash at varying ammonia/NOx ratios $(0.1$ - 1.0) to verify flow as accurately as possible with an ammonia mass balance. Measure ammonia distribution across reactor cross section at the Inlet and outlet.

2) Monitor ammonia oxidation at $\mathrm{NH}_{3} / \mathrm{NOx}$ molar ratios of 1.0 for low and high flue gas flow rates $(3000-7500 \mathrm{scfm})$, and low and high temperatures $\left(620^{\circ} \mathrm{F} \cdot 750^{\circ} \mathrm{F}\right)$.

The testing subcontractor will also assist in determination of "dead" and "delay" times of the measurement devices and control units. This will include determining time required for the system io reach equilibrium when starting or shutting off ammonia injection.

The testing contractor will also monitor $\mathrm{SO}_{3}$ levels while performing item 2 above, monitoring ammonia oxidation, to establish a baseline (also would assist in an opacity monitoring program * see Task 6).

\section{Task 3- Commissioning with Catalyst and Without Ammonia Injection}

After the catalyst is loaded into each of the reactors, SCS will establish the $\mathrm{O}_{2}$ concentration profile across the SCR reactor. When this requirement is satisfied, the following measurements will be performed:

1. Pressure drop across each catalyst laver.

2. NOx levels at reactor inlet and outlet.

3. $\mathrm{SO}_{2} / \mathrm{SO}_{3}$ conversion rate.

4. Isokinetic sampling and ash analyses from the reactor outlet.

Items 3 and $t$, above, will be performed by the testing subcontractor for each of the three flue gas flow rates to be tested in parametric testing:

$\begin{array}{lccc} & \text { Design } & \text { Minimum } & \text { Miximum } \\ \text { Large reactors } & 5000 \mathrm{scfm} & 3000 & 7500 \\ \text { Small reactors } & 400 \mathrm{scm} & 240 & 6(0)\end{array}$

The $\mathrm{SO}_{2} / \mathrm{SO}_{3}$ conversion rate will also be examined at the following temperatures: $620^{\circ} \mathrm{F}, 700^{\circ} \mathrm{F}$, and $750^{\circ} \mathrm{F}$. 
Task 4-Commissioning with Catalysts and with Ammonia Injection.

Once the SCR reactor train is ready for testing with ammonia injection, the following measurements will be made with an $\mathrm{NH}_{3}: \mathrm{NOx}$ ratio near 0.8 :

1. Pressure drop of each catalyst layer.

2. NOx concentration at reactor inlet and outlet with gas sampling system.

3. NOx reduction rate increase at reactor outlet as ammonia injection started.

4. NOx concentration rate of increase at reactor outlet as ammonia injection ceased.

5. Isokinetic sampling and ash analyses from reactor outlet.

6. Measure velocity, $\mathrm{NOx}$, and $\mathrm{NH}_{3}$ distribution across reactor outlet crosssection to verify continuous gas sampling results and in optimizing $\mathrm{NH}_{3}$ distribution/NOx reduction.

Items 5 and 6 , above, will be performed by the testing subcontractor. The ranges of the three major parameters (flue gas flowrate, temperature, $\mathrm{NH}_{3} / \mathrm{NOx}$ molar ratio) to be performed during this commissioning exercise, will match those to be performed during parametric testing for two temperatures (probably $700^{\circ} \mathrm{F}$ and $620^{\circ} \mathrm{F}$ ). These are described in the next section under Task 5.

\section{Task 5-Parametric Testing}

Once start-up data have been collected, the SCR reactor trains will be placed in longterm design operating conditions, which are as follows:

Flue Gas

Flow,SCFM

Large reactors

Small reactors

$$
5000
$$

400
Temperature, ${ }^{\circ} \mathrm{F}$

70()

700
$\mathrm{NH}_{3} / \mathrm{NOX}$

10.8

0.8

After operating for about 3 montlis in this base design mode, the SCR reactor trains will be sequentially evaluated in a series of parametric tests in order to evaluate the assumptions used to design the system for operation on high sulfur coal as well as to define the window of operating conditions in which the SCR system can operate. A preliminary test matrix defining the operations of this parametric test phase is shown in Table 2 and Figure 7. Each reactor will be put through this sequence of tests. It should be noted that the matrix in Figure 7 is preliminary and is shown for planning purposes to establish sample collection and analysis requirements.

The testing subcontractor will be responsible for conducting the items listed under "Special Measurements", with the exception of coal analyses. SCS will make arrangements for coal analyses through its laboratory personnel. This test plan is the basis for each testing subcontractor to prepare a bid in response to this Request for Proposal. It is anticipated that the test plan will be modified on the basis of discussions with DOE, catalyst suppliers, and other participants, and on the basis of a partial factorial statistical design by W. S. Pitts Consulting, Inc., a statistical consulting fïrm. 
Once parametric testing is completed, the reactor will be returned to either the original design operating conditions or operating conditions defined as optimal during the parametric testing, The reactor will operate in this long-term condition for twenty-four months while deNOx efficiency, slip $\mathrm{NH}_{3}, \mathrm{NH}_{4} \mathrm{HSO}_{4}$ formation and air preheater performance are monitored.

The parametric testing will be performed approximately every 3 months for each of the nine SCR reactors. Therefore, over the 2 year testing period, eight parametric evaluations will be performed for each reactor. During each parametric test, catalyst samples will also be collected and sent to each catalyst vendor for laboratory evaluations of the catalyst.

During long-term SCR catalyst durability testing, the air preheater's performance will be evaluated according to the tests performed by the testing subcontractor shown in Table 3.

The air heater tests will focus on several major objectives:

- Accurate simulation of large utility air heaters.

- Evaluation of the effects of deposition on air heater performance, particularly thermal efficiency and gas-side pressure drop.

- Evaluation of the effectiveness of sootblowing and water washing in removing deposits.

- Evaluation of the effects of ABS deposition on air heater corrosion.

With regard to simulation of large air heaters, sufficient measurements will be made to ensure representative gas and air velocities and a representative rate of air-to-gas leakage. Air leakage will be treated as a parameter in order to investigate the range of conditions encountered in full-scale units. In addition, flyash characteristics can play an important part in air heater deposition. Simulation of utility applications requires that the particulate loading and particulate characteristics entering the air heater be representative of full-scale conditions. Therefore, flyash mass loading, composition, and particle size will be measured at intervals during the test program by the testing subcontractor.

The major effects of an SCR system on air heater performance are expected to be seen in thermal efficiency and static pressure differentials. The standard measure of air heater thermal efficiency decreases as insulating deposits accumulate on the heating surface. Gas-side efficiency is calculated from gas and air temperatures around the air heater, which will be monitored continuously during the SCR demonstration. The measurement of static pressure differentials on the air heater gas and air sides is straightforward and will be done on a continuous basis. Pressure differentials are expected to undergo short-term increases in between sootblower operations and longer term increases in between water washing of the air heater. During a portion of the test program, sootblowing frequency and duration, and water washing frequency will be varied in order to determine the dependence of air heater performance measures on these variables. 
The deposits on the air heaters will be periodically removed by washing with water (probably on a quarterly schedule or as dictated by process requirements). Supplemental monitoring of this wash water will be conducted by the testing subcontractor for the parameters shown in Table 4. No compliance monitoring of aqueous process streams will be performed. 


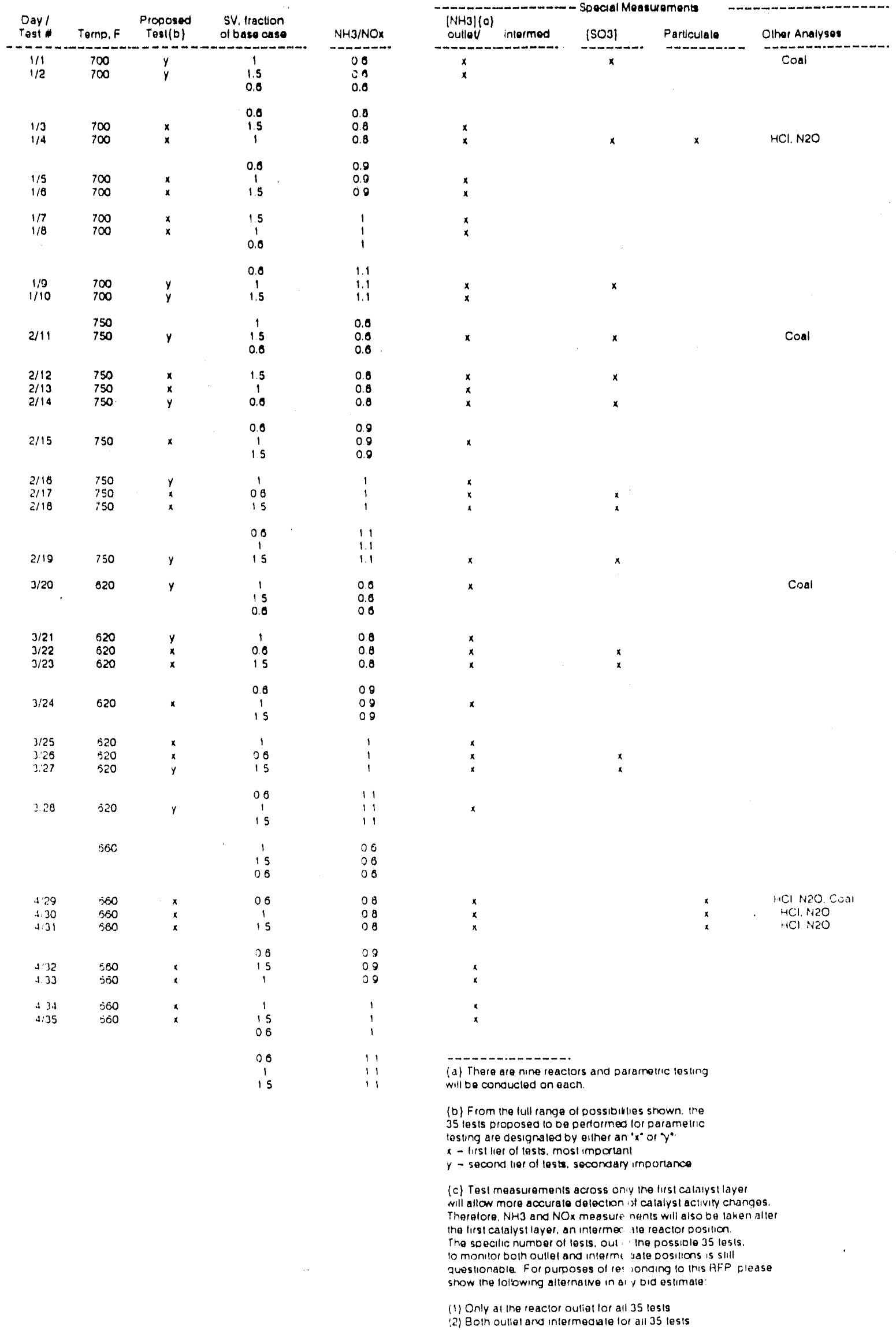


Figure 7

\section{Preliminary SCR Parametric Test Plan}

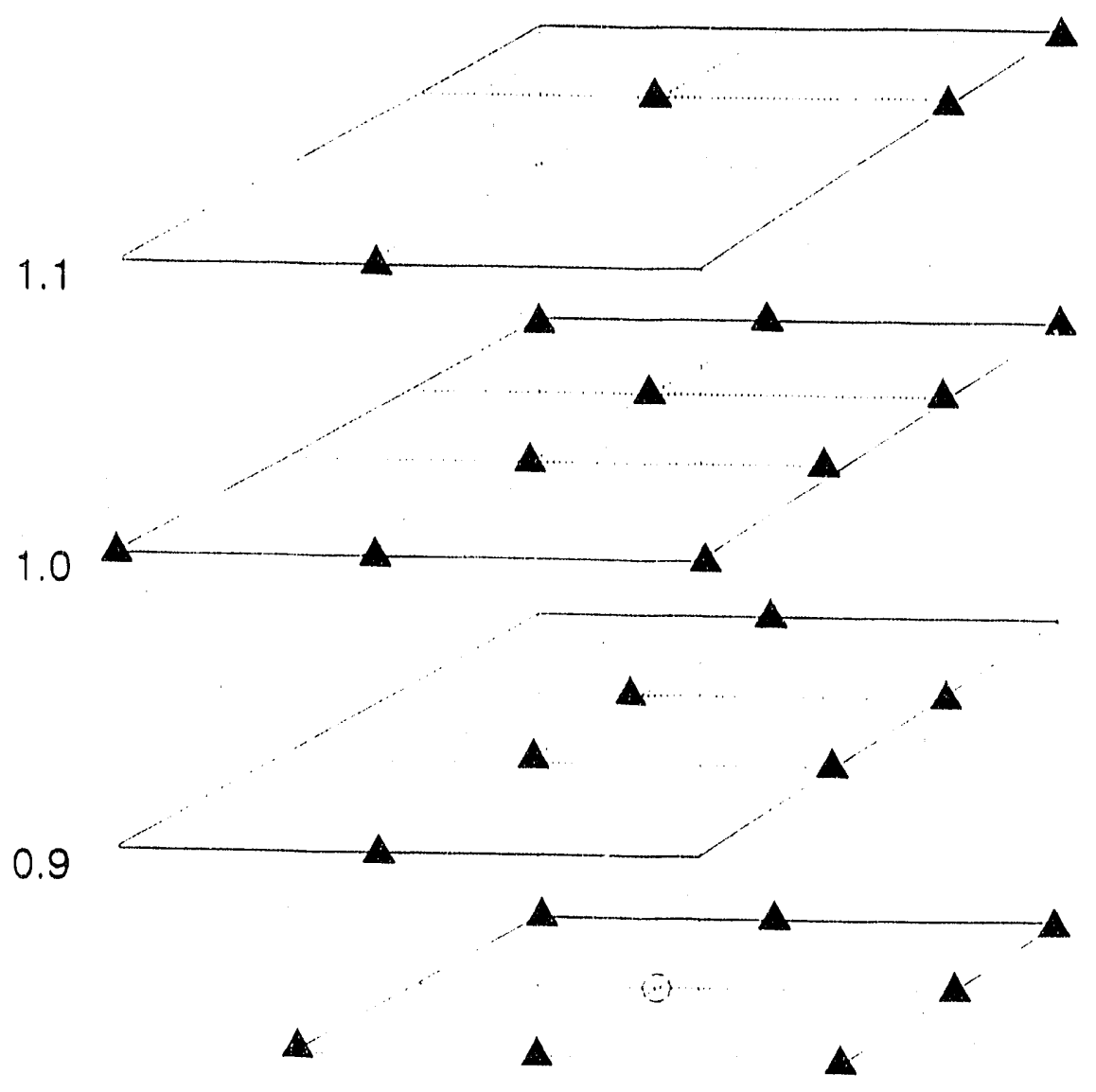

0.8

$\mathrm{NH3/NOX}$

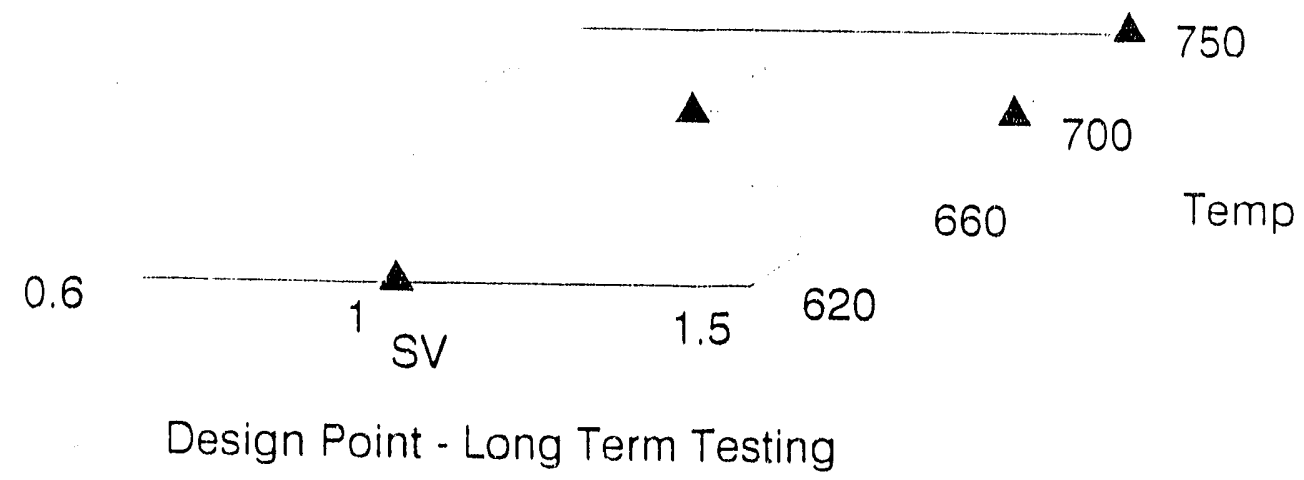


During long-term SCR catalyst durability testing, the air preheater's performance will be evaluated according to the tests performed by the testing subcontractor shown in Table 3.

The air heater tests will focus on several major objectives:

- Accurate simulation of large utility air heaters.

- Evaluation of the effects of deposition on air heater performance, particularly thermal efficiency and gas-side pressure drop.

- Evaluation of the effectiveness of sootblowing and water washing in removing deposits.

- Evaluation of the effects of ABS deposition on air heater corrosion.

With regard to simulation of large air heaters, sufficient measurements will be made to ensure representative gas and air velocities and a representative rate of air-to-gas leakage. Air leakage will be treated as a parameter in order to investigate the range of conditions encountered in full-scale units. In addition, tlyash characteristics can play an important part in air heater deposition. Simulation of utility applications requires that the particulate loading and particulate characteristics entering the air heater be representative of full-scale conditions. Therefore, flyash mass loading, composition, and particle size will be measured at intervals during the test program by the testing subcontractor.

The major effects of an SCR system on air heater performance are expected to be seen in thermal efficiency and static pressure differentials. The standard measure of air heater thermal efficiency decreases as insulating deposits accumulate on the heating surface. Gas-side efficiency is calculated from gas and air temperatures around the air heater, which will be monitored continuously during the SCR demonstration. The measurement of static pressure differentials on the air heater gas and air sides is straightforward and will be done on a continuous basis. Pressure differentials are expected to undergo short-term increases in between sootblower operations and longer term increases in between water washing of the air heater. Guring a portion of the test program, sootblowing frequency and duration, and water washing frequency will be varied in order to determine the dependence of air heater performance measures on these variables.

The deposits on the air heaters will be periodically removed by washing with water (probably on a quarterly schedule or as dictated by process requirements). Supplementil monitoring of this wash water will be conducted by the testing subcontractor for the parameters shown in Table 4 . No compliance monitoring of aqueous process streams will be performed. 
Table 3

AIR HEATER TESTING TO BE DONE BY TESTING SUBCONTRACTOR Large SCR Reactors Only Assumes Operating Under Long-Term Durability Conditions

Variables

$\mathrm{NH}_{3}$ concentration

$\mathrm{SO}_{3}$ concentration

$\mathrm{SO}_{3}$ concentration

$\mathrm{HCl}$ concentration

Flyash loading

Flyash composition

Flyash particle size

Flyash loading

Flyash composition

Flyash particle size

Flue gas flow rate

Basket corrosion rate
Primary Measurements

$\mathrm{AH}$ inlet $\mathrm{NH}_{3}$

SCR Reactor inlet $\mathrm{SO}_{3}$

$\mathrm{AH}$ inlet $\mathrm{SO}_{3}$

$\mathrm{AH}$ inlet $\mathrm{HCl}$

Loading (impactors)\}

Ash mineral

Impactors

Loading (impactors)\}

Ash minera

\} (1) $\mathrm{AH}$ inlet

Impactors

Flow element $\Delta \mathrm{P}$, ahead of $\mathrm{AH}$

Weight loss, metallographic examination, deposit composition and morphology
Measurement Interval

$3 / 3$ mo. $(\mathrm{lab})^{\mathrm{a}}$

$3 / 3$ mo. (lab)

$3 / 3$ mo. (lab)

$3 / 1$ mo. (lab)

$1 / 6 \mathrm{mo}$.

$1 / 1 \mathrm{mo}$

$1 / 6 \mathrm{mo}$.

$3 / 6 \mathrm{mo}$.

$3 / 1$ rno.

$3 / 6 \mathrm{mos}$

$3 / 1$ mo. (pitot)

$3 / 3 \mathrm{mos}$

Air heater wash discharge Water Wash composition

3/ 3-6 mo.

a May be same as regular reactor parametric tests. 
Table 4

\section{AQUEOUS STREAMS: INTEGRATED MONITORING SCHEDULE SCR DEMONSTRATION PROJECT}

\begin{tabular}{|c|c|}
\hline & Monitoring \\
\hline Parameter & $\begin{array}{c}\text { Air } \\
\text { Preheater } \\
\text { Wash Water }\end{array}$ \\
\hline
\end{tabular}

Total Suspended Solids

Total Dissolved Solids

$\mathrm{pH}$

Oil and Grease

Chloride

$\mathrm{NH}_{4} \mathrm{HSO}_{4}\left(\right.$ as $\left.\mathrm{SO}_{4}{ }^{2}\right)$
$1 / \mathrm{Q}[\mathrm{s}]$

$1 / \mathrm{Q}[\mathrm{s}]$

$1 / \mathrm{Q}[\mathrm{s}]$

$1 / \mathrm{Q}[\mathrm{s}]$

$1 / \mathrm{Q}[\mathrm{s}]$

Total Metals:

$\begin{array}{lll}\text { Aluminum } & \text { Copper } & \text { Mercury } \\ \text { Arsenic } & \text { Iron } & \text { Nickel } \\ \text { Cadmium } & \text { Lead } & \text { Selenium } \\ \text { Chromium } & \text { Manganese } & \text { Zinc }\end{array}$

"Monitoring frequency: $1 / \mathrm{W}=$ one time per week; $1 / 2 \mathrm{~W}=$ one time every two weeks: and $1 / Q=$ one time per quarter year.

"Letter within brackets indicates monitoring type: $[\mathrm{c}]$ = Corpliance monitoring; and [s] = Supplemental monitoring for duration of SCR demon-project only.

"Refers only to the air preheater wash that is associated with the demonstration unit. The actual sampling frequency will depend on the required washing frequency.

${ }^{\mathrm{J}}$ Wash frequency has not yet been determined. Wash water will be monitored during each wash cycle, up to 4 times per year.

"Backgound numbers for this point shall be as established by state and federal regulations under Gulf Power Company's NPDES permits. Background numbers tor the test period only may utilize actual discharge numbers into the pond, to achieve an increase/decrease in the parameters for this test only. All numbers for these parameters achieved during the testing period shall have the actual effluent numbers existing at the time of the test subtracted from them to obtain a true value for the increase/decrease discharge. None of the test results shall be utilized by the regulatory agencies to modify Gulf Power Company's existing permits for the discharges from these units at this point. 
As stated previously, air heater corrosion is an important issue in the application of SCR technology. Ammonium bisulfate is acidic in nature and attacks low alloy steels similarly to sulfuric acid. Moreover, the presence of deposits often provides conditions for accelerated localized attack due to the concentration of acids underneath the deposit layer. In order to evaluate air heater corrosion, selected elements will periodically be removed from the air heaters and inspected. The testing subcontractor will perform the following services:

- Samples of deposits on the element surface will be sectioned and characterized with respect to composition, morphology, and strength.

- Corrosion products on the metal surface will be analyzed for cations and anions.

- The element itself will be cleaned free of deposits and subjected to examination.

The principal determinations will be loss of metal due to generalized corrosion and the depth and character of any localized pitting. Weight loss determinations will be attempted, although the accuracy of such measurements is questionable with large samples and short exposure periods. The examination of element sections under magnification will be applied to provide qualitative estimates of metal loss and corrosion mechanisms.

To complete the assessment of air heater corrosion, measurements of flue gas acid concentrations and acid dewpoint will be done by the testing contractor on a periodic basis. Principal acids of interest are $\mathrm{H}_{2} \mathrm{SO}_{4}$ and $\mathrm{HCl}$. [For purposes of responding to this RFP, the testing subcontractor may assume the acid measurements are the same as shown in the test plan $\left(\mathrm{SO}_{3}, \mathrm{HCl}\right)$ for parametric testing and that acid dewpoint will be measured on a daily basis using a commercially available acid dewpoint meter. Please include in your RFP response any previous experience of suggestions for this testing.]

Data collection during the parametric testing will include both automated and manu data collection. The prototype SCR design includes a sophisticated, automated data collection system that will collect the following data:

\section{By Southern Company Services}

- Flue gas flowrates (from venturi $\Delta \mathrm{Ps}$ ), pressure drops, from which static pressures can be inferred) and temperatures will be monitored systematically through the use of a programmed sequencing access of sensing elements placed in the flue gas stream. Data output from the sensing elements will be fed to a central computer/data acquisition and logging system for instantaneous display, real-time trend analysis and permanent data storage.

- Certain flue gas components will be analyzed through an automated, dilution/extractive gas analysis system. The system described is in Attachment B. This automated sampling system will analyze tor: $\mathrm{NOX}, \mathrm{O}_{3}$ $\mathrm{SO}_{2}, \mathrm{CO}_{2}$, or $\mathrm{CO}$. 
- Other gaseous species $\left(\mathrm{SO}_{3}, \mathrm{NH}_{3}, \mathrm{HCl}\right.$, and $\left.\mathrm{N}_{2} \mathrm{O}\right)$ will be analyzed via wet chemical techniques. These samples will be collected mariually by an on" site chemical analysis staff through the use of established wet chemical gas sampling and analysis methods. These data will be entered into the computerized data logging system to supplement the operatlonal data and alutomated gas compositional data collected as described above.

With installation and use of these data connection techniques for monitoring the operations and performance of the prototype SCR facility, the prototype plant will be equipped with the state-of-the-art in process control/diagnostic/monitoring instrumentation. This should allow rapid evaluation of the critical process parameter governing SCR performance. In addition, since all data will be stored electronically, provisions will be made to transmit the prototype plant data from the plant site at Plant Crist in Pensacola, Florida to SCS headquarters in Birmingham using the SES internal telecommunications system. This will allow process engineers at the site and in Birmingham (as well as project/program management) to have instant access to the operational and deNOx performance of the prototype SCR facility.

\section{Task 6-Opacity Assessment (Optional)}

SCR catalysts are known to promote $\mathrm{SO}_{2}$ oxidation to $\mathrm{SO}_{3}$. Based on initial site characterization, it is assumed that existing $\mathrm{SO}_{3}$ levels in the flue gals at Plant Crist are about 15 to $20 \mathrm{ppm}$. These levels may increase to about 30 to $40 \mathrm{ppm}$ for the flue gas exiting the SCR reactors.

It would be desirable to evaluate the potential impact of this increased $\mathrm{SO}_{3}$ level (and possibly $\mathrm{NH}_{3}$ ) upon stack gas opacity. Therefore, we request that the testing subcontractor propose an adequate methodology for performing such an opacity assessment. Please include information on all requirements for conducting this evaluation (apparatus, analyses, manpower requirements, costs, etc.). SCS considers this an optional task and will make a decision whether or not to perform this task based upon evaluation of proposed responses.

\section{Task 7 - Reporting and Project Management}

Prior to start-up of the SCR pilot plant, the testing subcontractor will work closely with the onsite process engineer and other SCS staff to establish the most effective means of transferring testing results and data into the overall project's electronic storage database. The technical reports to be supplied by the testing subcontractor are summarized below.

- Final report under Task 1 summarizing results of flue gas extraction system performance by mapping plant ductwork, SCR ductwork manifold, and reactor Inlets.

- Quality Assurance/Quality Control Plan which describes the approaches to ensure the producing of data of known and acceptable quality for this project. This may include following of accepted sampling and analytical procedures, adequate documentation, sample tracking, quality control checks and corrective action mechanisms (including calibration, duplicate analyses, etc.), measurement 
precision and accuracy assessment, data revlew, record keeping, valldation and quality assessment.

- Reports (probably on a quarterly basis or as dictated by process requirements on the testing program) on the results of the air heater testing program including the following: gaseous components monitoring, particulate measurements, basket corrosion analyses, and supplemental wash water monitoring. The report would Include data, signifleant results of the date and its implication to the program, and potential measures that may need to be taken.

- Monthly technical "letter" reports describing an overall status summary and reporting any specific exceptions to standard performance or quality data.

- If the optional Task 6 is pursued, opacity assessment, intermediate and final reports on the results will be required.

For purposes of responding to this RFP, the proposer should plan to attend the following meetings at Plant Crist in Pensacola, Florida:

- Monthly project review meetings will be held cluring the Construction phase of this project. For estimating purposes, the testing subcontractor should assume attendance for the months of July - October, 1992.

- Six Quarterly Technical Progress Review meetings will be held during the Process Evaluation period. These are tentatively scheduled for March, June and September in each of 1993 and 1994.

- Three Project Review meetings are also now scheduled for April and November of 1992, and for January 1994.

\section{PROJECT MANAGER AND COORDINATION}

The designated SCS Project Manager will be kept fully informed during the period of this research effort. Briefings on the progress of the Work, in addition to the reporting schedule listed, will be provided as required.

\section{PERIOD OF PERFORMANCE}

The anticipated period of performance is 27 months, commencing on or about Vovember $1,1992$.

\section{COST}

Proposer shall supply cost detail in a form sufficient to meet U.S. DOE auditing requirements. Some of the cost details required for adequate consideration and auditing purposes include the following:

1. Direct materials, labor, and subcontracts: including (a) job classification/titles, (b) labor hours, (c) hourly rates, and (d) labor costs per classification.

2. Overhead rates and costs.

3. Travel expenses with descriptions of destination, transportation means, subsistence, and cost breakdowns associated with each. 
4. Other Dlrect Costs: units, rntes, and cost.

5. General and Administrative Expense: percentage and costs.

6. Other Costs Including anount of any fees.

7. Escalation factors anticipated to cover general labor salary increases and contractors rates for overheads, $G$ \& $A$, etc.

The Proposer shall submit a cost breakdown by separately identifiable tasks. Also, Proposer shall provide one overall cost summary combining the total estimated costs for all tasks.

Cost will be a consideration in selection of a contractor.

\section{REPORTS: Cost and Tectricical}

After execution of the contract, the Testing Subcontractor shall provide an initial forecast of costs to be incurred monthly during the term of the contract. Thereafter the contractor shall provide a monthly report of incurred costs.

The Testing Subcontractor shall submit to the project manager, on a monthly basis, letter technical progress reports with respect to the Work. The Testing Su'scontractor will also provide the other technical reports described under Task 7 and dates under Schedule of Deliverables, Where applicable, the Testing Subcontractor will submit final reports to SCS in preliminary form for review and comment in less than thirty (30) days after completion of each task.

\section{KEY PERSONNEL}

The Proposer shall identify those individuals who are to be considered key personnel for performance of the Work under this Request for Proposal. Any change in key personnel associated with the project shall not be made without the prior written approvial of the SCS Project Manager.

\section{SUBCONTRACTING}

Proposers may elect to arrange subcontracting with others. If such arrangements are proposed, the areas of investigation shall be identified in conjunction with the actual investigator. All subcontracting arrangements are subject to the terms and conditions set forth in the Agreement between SCS and the Proposer.

\section{SCHEDULE OF DELIVERABLES}

Technical Reports

- Monthly

- Per Task 7: 1)

Task 1 summary report (conclusion of Task 1)

2) QA/QC Plan - (Prior to start-up)

3) Air Heater Testing Program (probably quarterly) 
4) Optional Opacity Assessment (Intermediate reports as deemed necessary by testing results and one final summary report)

\section{PROPOSALCONTENTS OUTLINE}

Proposers may bind their technical and cost proposals together or separately. The technical proposal should be limited to 100 pages, double spaced (standard 8.1/2" $\times 11^{\prime \prime}$ page, 10 or 12 pitch, no reduction of print size), excluding resumes, and organized per the following outline.

Introduction

- Key features of proposal

- Key participants (organizations and indlviduals) and relevance of their experience.

\section{Techinicul Discussions}

- Key technical issues and solution approaches

- Responses to following requests in Statement of Work:

- Under Task 1 , extensive measuring during start-up of the performance of the flue gas extraction system by mapping of (a) main power plant ductwork at extraction scoop location, (b) duct manifold for SCR reactors, and (c) inlet to each SCR reactor for the following as function of low and high boller loads:

- particulate mass loading, size distribution, and composition

- $\quad$ flue gas velocity and temperature profiles, duct static pressures

- $\quad \mathrm{NO}, \mathrm{NO}_{\mathrm{x}}$ and $\mathrm{O}_{2}$ concentration profiles.

Additional flue gas composition characterization will be performed for each of the continuous gas sampling points to verify that the gas sampling system is producing representative data.

- Under Task 1, baseline measurements during start-up of $\mathrm{HCl}, \mathrm{NH}_{3}, \mathrm{SO}_{3}$, and $\mathrm{N}_{2}($ ). $\mathrm{SO}_{3}$ measurements will include $\mathrm{SO}_{2}$ to $\mathrm{SO}_{3}$ conversion rates across electric healers and SCR reactors.

- Under Task 1, Measure levels of trace metals (e.g., $A_{s}, H_{g}, P_{b}, C_{d}$ ) in the gasphase and on the fly-ash.

- Propose and justify analyses methods for each test required by this RFP.

- Propose techniques for qualitative tracking of particulate characteristic changes.

- Under Task 2, monitor ammonia distribution, across the reactor inlet/outlet, in gas and in fly-ash, at varying $\mathrm{NH}_{3} / \mathrm{NO}_{x}$ ratios, and use results to assist SCS operations in optimizing $\mathrm{NH}_{3}$ injection. 
- Under Task 2, monitor ammonia oxidation at varying flue gas flow rates and temperatures for $\mathrm{NH}_{3} / \mathrm{NO}_{x}$ ratio of 1,0 .

- Under Task 2, assist in determining "dead" and "delay" times of measurement devices and control units.

- Under Task 2 monitor $\mathrm{SO}_{3}$ levels.

- Under Task 3 monitor $\mathrm{SO}_{2}$ to $\mathrm{SO}_{3}$ conversion rate for various flue gas flow rates and temperatures.

- Under Task 3, sampling and analyses of ash from reactor outlet at varying flue gas flow rates.

- Under Task 4, sampling and analyses of ash from reactor outlet and measuring of velocities, NOx, and gaseous slip ammonia from reactor outlet, for varying flue gas flow rates, temperature, and $\mathrm{NH}_{3} / \mathrm{NO}_{x}$ ratios.

- Under Task5, perform special measurements required under parametric testing, with 35 test array, including analyses for $\mathrm{NH}_{3}, \mathrm{SO}_{3}$, particulate, $\mathrm{HCl}$, and $\mathrm{N}_{2} \mathrm{O}$.

- Under Task 5, perform air heater performance testing to include the following:

- monitor $\mathrm{NH}_{3}, \mathrm{SO}_{3}$, and $\mathrm{HCl}$ at air heater inlet and $\mathrm{SO}_{3}$ at reactor inlet.

- measure fly-ash mass loading, composition, and particle size.

- check flue gas flow rate with pitot.

- monitor of air heater wash water for total suspended solids, total dissolved solids, $\mathrm{pH}$, chlorides, $\mathrm{NH}_{4} \mathrm{HSO}_{4}$, and total metals.

- evaluate basket corrosion through weight loss, metallographic examination, deposit composition and morphology.

- monitor flue gas acid concentrations and acid dewpoints.

- Under Task 6, propose evaluation plan for conducting an alssessment of SCR impact on stack gas opacity.

- Under Task 7, include requirements for establishing effective transfer of data and results into the overall project data base, providing required reports to SCS, and attending scheduled meetings.

\section{Technical Plan}

- Technical approach by task

- Schedule

- Labor-hour allocations by task for each key personnel as well as for categories of junior technical and support staff

- Statement of work suitable for contract 
Project Organization and Management Plan

Relevant Experience

- SCR

- R\&D emissions testing at utility sites

- Measurements for species mentioned in Statement of Work

Resumes

Costs

EVALUATION CRITERIA

The following evaluation criteria will be used by SCS in evaluating proposals submitted in resporise to this RFP. Although the criteria are listed in clescending order of priority, proposers should not minimize the importance of an adequate response in any area, as all of the criteria listed will be considered in determining SCS's selection. Willingness to accept SCS contract terms and conditions will be a consideration in the selection of a contractor.

\section{Evaluation Criteria}

A. Proposer's understanding and technical approaches to meet of the project requirements

B. Qualifications of key personnel and other assigned personnel

C. Cost

D. Proposer's organization and management plan

E. Corporate experience and past performance

F. Corporate or company resources (including financial, facility, and other resources) 

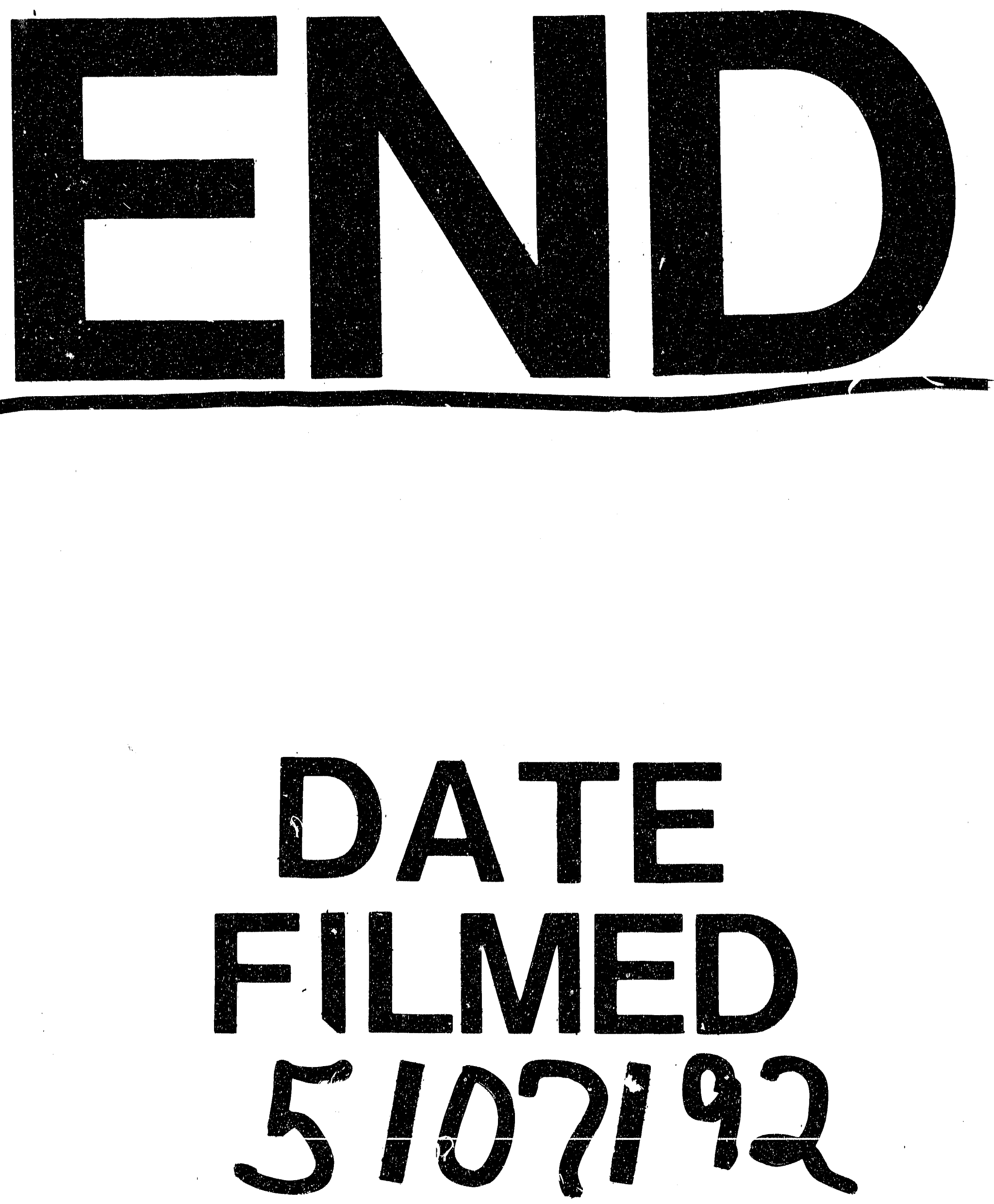
